\title{
Infection prevention in the operating room anesthesia work area
}

\author{
L. Silvia Munoz-Price MD, $\mathrm{PhD}^{1,}$, Andrew Bowdle MD, PhD², B. Lynn Johnston MD³ , Gonzalo Bearman MD, \\ $\mathrm{MPH}^{4}$, Bernard C. Camins MD, MSc${ }^{5}$, E. Patchen Dellinger $\mathrm{MD}^{2}$, Marjorie A. Geisz-Everson PhD, CRNA ${ }^{6}$, \\ Galit Holzmann-Pazgal $M D^{7}$, Rekha Murthy $\mathrm{MD}^{8}$, David Pegues $\mathrm{MD}^{9}$, Richard C. Prielipp MD, MBA, FCCM ${ }^{10}$, \\ Zachary A. Rubin $\mathrm{MD}^{11}$, Joshua Schaffzin MD, PhD ${ }^{12}$, Deborah Yokoe MD, $\mathrm{MPH}^{13}$ and David J. Birnbach MD, \\ $\mathrm{MPH}^{14}$ \\ ${ }^{1}$ Froedtert \& the Medical College of Wisconsin, Milwaukee, Wisconsin, ${ }^{2}$ University of Washington, Seattle, Washington, ${ }^{3}$ Dalhousie University, Halifax, Nova \\ Scotia, ${ }^{4}$ Virginia Commonwealth University School of Medicine, Richmond, Virginia, ${ }^{5}$ University of Alabama at Birmingham, Birmingham, Alabama, ${ }^{6}$ University of \\ Southern Mississippi, Hattiesburg, Mississippi, ${ }^{7}$ Baylor College of Medicine, Houston, Texas, ${ }^{8}$ Cedars-Sinai Medical Center, Los Angeles, California, ${ }^{9}$ University of \\ Pennsylvania, Philadelphia, Pennsylvania, ${ }^{10}$ University of Minnesota, Minneapolis, Minnesota, ${ }^{11}$ David Geffen School of Medicine at UCLA, Los Angeles, \\ California, ${ }^{12}$ Cincinnati Children's Hospital Medical Center, Cincinnati, Ohio, ${ }^{13}$ University of California San Francisco School of Medicine, San Francisco, \\ California and ${ }^{14}$ University of Miami Miller School of Medicine, Miami, Florida
}

(Received 15 October 2018; accepted 19 October 2018)

\section{Purpose}

The potential for clinically significant microbial cross transmission in the intraoperative environment poses a threat to patient safety. A growing body of literature has shown contamination in the anesthesia work area, including the anesthesia medical work cart, stopcocks, laryngeal masks and laryngoscope blades, touchscreens, and keyboards, as well as on providers' hands, resulting in transmissions, healthcare-associated infections, and increased risk of patient mortality.

The authors acknowledge that the operating room (OR) is a challenging environment in which to affect ideal infection prevention and control practices. In addition, infection prevention and control policies specific to anesthesia care in the OR are not universal; audits of infection prevention practices are not routine; and consequently, providers may not have clarity on expected practices and behaviors. Studies have reported problematic practices by anesthesia providers, including use of multiple-dose vials for $>1$ patient, $<100 \%$ use of gloves for airway management, failure to perform hand hygiene $(\mathrm{HH})$ after removing gloves, and entry into anesthesia cart drawers without performance of $\mathrm{HH}$. This guidance provides recommendations specific to the anesthesia work area to improve infection prevention through $\mathrm{HH}$, environmental disinfection, and implementation of effective improvement efforts.

Furthermore, SHEA acknowledges significant challenges to implementing the array of infection prevention and control recommendations to affect OR culture in general, and the work flow of anesthesia providers in particular. Facility administrators will need to actively collaborate with anesthesia department leaders to build an implementation plan that is timely,

Author for correspondence: L. Silvia Muñoz-Price, Medical College of Wisconsin, 8701 Watertown Plank Road, Milwaukee, WI 53226. E-mail: smunozprice@mcw.edu

Cite this article: Munoz-Price LS, et al. (2019). Infection prevention in the operating room anesthesia work area. Infection Control \& Hospital Epidemiology 2019, 40, 1-17. doi: $10.1017 /$ ice.2018.303 comprehensive, and multidisciplinary, and that will allocate hospital resources to educate healthcare personnel and to acquire new infection prevention and control components (eg, single-use laryngoscopes). Facilities should consider this guidance document in revisions of their anesthesia OR policies.

This guidance builds on the foundational premise that all facilities where anesthesia services are delivered have formal infection prevention and control programs. Essential elements of these programs include, but are not limited to, policies and procedures for $\mathrm{HH}$, safe preparation and delivery of intravenous medications, and environmental cleaning and disinfection. All individuals involved in these procedures require training appropriate to their tasks, as well as regular skills assessments.

\section{Authors}

The writing panel (the authors) consists of current and past members of the SHEA Guidelines Committee and representatives of organizations that partnered with SHEA to write this document: Dr. David J. Birnbach, American Society of Anesthesiologists (ASA); Dr. Richard C. Prielipp, Anesthesia Patient Safety Foundation (APSF); and Dr. Marjorie Geisz-Everson, American Association of Nurse Anesthetists (AANA). All panel members served as volunteers.

\section{Intended Use}

SHEA develops expert guidance documents (EGs) for topics of relatively narrow scope that lack the level of evidence required for a formal guideline developed using the GRADE or a similar systematic methodology but are important in provision of safe, effective healthcare. As such, systematic grading of the evidence level is not provided for individual recommendations. Each EG is based on a synthesis of limited evidence, theoretical rationale, 
current practices, practical considerations, writing group opinion, and consideration of potential harm where applicable.

No EG can anticipate all clinical situations, and this guidance document is not meant to be a substitute for individual clinical judgment by qualified professionals.

\section{Methods}

\section{Document development}

This expert guidance document follows the process outlined in the "Handbook for SHEA-Sponsored Guidelines and Expert Guidance Documents." The topic was among those proposed and selected by the SHEA Guidelines Committee (GLC). The subsequent manuscript proposal developed by the GLC was approved by the SHEA Publications Committee and the SHEA Board of Trustees.

The writing panel developed PICO-style (population, intervention, control, and outcomes) questions based on themes identified by the panel. These questions were used in the development of search terms (medical subject heading [MeSH] and text word), and both the questions and search terms were voted on by the panel until unanimous approval was achieved. The writing panel identified the period from which articles would be collected as January 1, 1990, to June 30, 2016. Only English language articles were included. The lists of articles generated from the searches were reviewed by a primary reviewer and secondary reviewer for inclusion. For this topic, the authors conducted 2 surveys of the SHEA Research Network (SRN) and subsets of the American Association of Nurse Anesthetists (AANA), the American Society of Anesthesiologists (ASA), and the American Academy of Anesthesiologist Assistants (AAAA) membership.

SHEA EGs are developed with a formalized process for reaching expert consensus. Recommendations are listed with rationale statements that consider relevant evidence as well as the consensus of the group. Consensus around recommendations and rationale was determined via an anonymous comment period. For this EG, full consensus was achieved.

\section{Review and endorsement}

The document was reviewed and approved by the SHEA Guidelines Committee and the SHEA Publications Committee and was endorsed by the SHEA Board of Trustees, the AAAA, the AANA, the Association for periOperative Registered Nurses (AORN), and the Anesthesia Patient Safety Foundation (APSF). The ASA provided a letter of support with qualifications (Appendix 1).

\section{Surveys}

\section{SHEA Research Network (SRN)}

In December 2016, a survey was sent to SHEA Research Network (SRN) members to gather information on infection prevention and control policies and practices for anesthesia providers in the OR setting. In total, 59 individual healthcare epidemiologists at their healthcare institutions responded (43 United States members and 16 international members) from the 130 invited to participate, for a response rate of $45.8 \%$.

The minority of SRN respondents (35.6\%) reported having infection prevention and control policies specific to anesthesia practice in the OR, with international respondents (10 of 16) more likely than US respondents ( 11 of 43$)$ to have such policies $(P=.008)$. For respondents answering that there were no $(n=35)$ or unknown $(n=7)$ policies specific to anesthesia, $97.5 \%$ reported the expectation that anesthesia provider practice in the OR would be in compliance with institutional policies (supplementary Table 1).

Only 3 respondents reported that their facility has a policy that allows anesthesia providers to perform $\mathrm{HH}$ on gloved hands as an alternative to changing gloves followed by $\mathrm{HH}$, and in one instance this was a written policy. Also 7 respondents answered that anesthesia providers are allowed to wear 2 sets of gloves during airway management and to remove the outer glove without performing additional $\mathrm{HH}$, although in no instance was this a written policy. Among respondents who were aware of their facility's practices, $34.9 \%$ and $21.6 \%$ of institutions routinely used single-use laryngoscopes or videolaryngoscopes, respectively. Generally, facilities audited anesthesia providers' infection prevention and control practices in the OR when there was a concern about practices (52.5\%), although 13 respondents (22\%) reported a monthly audit. Only 4 facilities $(6.8 \%)$ never conducted audits (supplementary Table 2).

\section{Survey to members of $A S A, A A N A$, and $A A A A$}

The panel sent a survey focused on practices that providers follow while giving care in the OR setting to 3 groups of anesthesia providers in March 2017; 5,000 members of ASA; 5,000 members of AANA, and 1,761 members of the AAAA. We received responses from 396 physicians $(8 \% ; 113$ in academic practice, 277 in private practice, 6 in training), 246 nurse anesthetists (5\%; 236 certified, 10 in training), and 70 anesthesiologist assistants (4\%; 56 certified, 14 in training). The majority had $>10$ years in practice $(0-10$ years, $27.3 \%$; $11-30$ years, $49.4 \%$; $>30$ years, $23.3 \%)$. Two-thirds of respondents reported having infection prevention and control guidelines specific for anesthesia services in their institution (supplementary Table 3).

Alcohol-based hand rub (ABHR) was generally readily available within the anesthesia work area (always or usually: 93.8\%) and was located at entry points to every OR (always or usually, 92.3\%). Respondents identified the following barriers to $\mathrm{HH}$ : lack of time in emergency situations (58.3\%), lack of time in general (44.2\%), skin factors (35.8\%), HH equipment not easily accessible (27\%), and lack of support from OR personnel for HH-related workflow interruptions (15.5\%) (supplementary Table 4).

Anesthesia providers identified several barrier precautions used for inserting central lines: mask (94.4\%), sterile gloves (93.8\%), gown (88\%), cap (91.6\%), and full drape $(79.2 \%)$. The practice was different for placing arterial lines, with providers using all barrier elements less frequently: masks, $82 \%$; sterile gloves, $74.2 \%$; gown, $10.9 \%$; cap, $76.8 \%$; full drape, $3.7 \%$ ). Almost half did not use a drape (48.1\%).

Institutions provided feedback variably on their departments' adherence to $\mathrm{HH}$ (never, $40.9 \%$; every 6-12 months, 34.9\%; quarterly, 24.2\%) and other infection prevention and control practices and procedures (never, 42.3\%; every 6-12 months, $36.8 \%$; quarterly, $20.9 \%$ ).

\section{Discussion}

Given the low response rate from anesthesia providers, it is difficult to determine how generalizable findings are to all 
institutions and all anesthesia providers. If respondents represent providers who are most interested in following infection prevention and control practices, these results likely overestimate adherence with infection prevention and control in the OR setting; nonetheless, some conclusions may be drawn:

1. Infection prevention and control policies specific to anesthesia care in the OR are not universal in US healthcare facilities.

2. Audits of infection prevention and control practices are not routine.

3. Not all anesthesia work areas are cleaned and disinfected between every patient, and the anesthesia cart is an item of risk for cross contamination.

4. Certain anesthesia provider practices remain problematic, especially the use of multiple-dose vials for $>1$ patient, $<100 \%$ use of gloves for airway management, lack of $\mathrm{HH}$ after removing gloves, and entry into anesthesia cart drawers without $\mathrm{HH}$.

The authors acknowledge that the OR is a challenging environment in which to affect ideal infection prevention and control practices, but we note the opportunity for improvement.

\section{Guidance Statement}

Hand hygiene

\section{Which activities in anesthesia care should always result in hand hygiene $(\mathbf{H H})$ ?}

Recommendation: $\mathrm{HH}$ ideally should be performed according to the WHO 5 Moments for Hand Hygiene. The authors recommend that $\mathrm{HH}$ be performed at the minimum before aseptic tasks (eg, inserting central venous catheters, inserting arterial catheters, drawing medications, spiking IV bags); after removing gloves; when hands are soiled or contaminated (eg, oropharyngeal secretions); before touching the contents of the anesthesia cart; and when entering and exiting the OR (even after removing gloves).

Rationale: Previous observational studies have reported that if the WHO 5 Moments for Hand Hygiene is used as the standard, the indications for $\mathrm{HH}$ among anesthesia providers in the OR can be as high as 54 per hour, leading to nonadherence rates of $83 \%{ }^{2}$ These findings have led some investigators to conclude that applying the WHO 5 Moments $^{1}$ in the anesthesia work area, especially during induction, is logistically unfeasible. ${ }^{3}$ MuñozPrice et $\mathrm{al}^{4}$ showed that increasing access to ABHR led to an increase in the number of times $\mathrm{HH}$ was performed by anesthesiology staff during a surgical procedure. ${ }^{4}$ Another study suggests that wearable ABHR dispensers improve $\mathrm{HH}$ adherence among anesthesia providers. ${ }^{5}$ Koff et $\mathrm{al}^{6}$ showed that the use of a wearable ABHR dispenser capable of recording $\mathrm{HH}$ events decreased the contamination rate of intravenous tubing in the operating room (OR). In a multisite randomized controlled trial, Koff et $\mathrm{al}^{7}$ also showed that providing wearable dispensers to anesthesia providers resulted in an 8-fold increase in the number of times $\mathrm{HH}$ was performed compared to rooms where only wall-mounted ABHR dispensers were available.

\footnotetext{
${ }^{1}$ WHO 5 Moments of Hand Hygiene: (1) before touching a patient; (2) before clean/ aseptic procedures; (3) after body fluid exposure/risk; (4) after touching a patient; and (5) after touching patient surroundings.
}

\section{Should providers wear double gloves during airway management and discard the outer glove immediately after airway manipulation?}

Recommendation: To reduce risk of contamination in the OR, providers should consider wearing double gloves during airway management and should remove the outer gloves immediately after airway manipulation. As soon as possible, providers should remove the inner gloves and perform $\mathrm{HH}$.

Rationale: Anesthesia providers' hands may become contaminated with upper-airway secretions while providing airway management and endotracheal intubation. Providers may not be able to perform $\mathrm{HH}$ during this time, and cross contamination of the anesthesia work area can occur. The literature search identified 2 randomized trials and 1 anecdotal report related to the strategy of using double gloves to decrease contamination in the $\mathrm{OR}^{8-10}$ The 2 trials found a significant decrease in OR contamination $(P<.001)$ when double gloves were used during airway manipulation and/or intubation and the outer layer was removed after intubation. Despite the significant decrease in contamination, it was not completely eliminated; therefore, anesthesia providers should remove the inner layer of gloves as soon as possible and perform $\mathrm{HH}$. Although these investigations took place in a simulated OR with anesthesia residents, the authors believe that the results can be generalized to actual ORs in hospitals.

\section{Where should facilities locate alcohol-based hand rub (ABHR) dispensers in the OR?}

Recommendation: The authors recommend that facilities locate ABHR dispensers at the entrances to ORs and near anesthesia providers inside the OR in order to promote frequent $\mathrm{HH}$. Several studies have demonstrated that wearable ABHR dispensers with audible reminders increase the frequency of $\mathrm{HH}$ as well as the potential to decrease the incidence of HAI. While the specific wearable devices used in these studies are not currently available, the authors recommend that facilities consider suitable wearable ABHR dispensers with automatic reminders when commercially available. ABHR dispensers should be located in accordance with applicable national and local fire safety standards and codes. Additionally, the authors recommend that the facility delegate the filling of the ABHR dispensers to designated personnel and regularly ensure compliance with this practice.

Rationale: Locating ABHR dispensers at entrances to ORs facilitates the recommended practice of performing $\mathrm{HH}$ before entry and after exiting the room, and locating $\mathrm{ABHR}$ dispensers on the anesthesia machine has been associated with a modest increase in the frequency of $\mathrm{HH}^{4}$ Researchers in one study found that the use of a wearable ABHR dispenser with an audible reminder resulted in a significant increase in $\mathrm{HH}$ and reduction in anesthesia work area contamination, IV tubing contamination, and healthcare-associated infection ${ }^{6}$; however, a subsequent similar study found an increase in the rate of $\mathrm{HH}$ but no effect on the rate of healthcare-associated infection. ${ }^{7}$

A variety of local and national fire-prevention standards and codes may restrict the placement of ABHR dispensers on top of the anesthesia machine. For example, the National Fire Protection Association (NFPA) 101: Life Safety $\operatorname{Code}^{11}$ stipulates the maximum allowable volume of an individual ABHR dispenser to be $1.2 \mathrm{~L}$ and requires that dispensers be separated horizontally by at least $122 \mathrm{~cm}$ (48 inches), and that dispensers be at least $2.5 \mathrm{~cm}$ 
(1 inch) away from an ignition source. However, the incidence of fire from ABHR dispensers appears to be extremely small. ${ }^{12,13}$

\section{Can the anesthesia provider apply ABHR on gloves that are being worn during a case, rather than removing the gloves, performing $\mathrm{HH}$, and then replacing a new set of gloves if contaminated?}

Recommendation: Changing gloves with $\mathrm{HH}$ between doffing and donning is the preferred method of disinfection. Current data are inadequate for the authors to either support or discourage the procedure of using ABHR on gloved hands or to determine whether application of foam or gel affects glove integrity. However, application of ABHR to gloved hands might be better than to not perform any $\mathrm{HH}$ when doffing and donning are not feasible.

Rationale: The clinical practice of disinfecting latex or nitrile disposable gloves with $\mathrm{ABHR}$ is an interesting but currently uncommon practice (supplementary Table 4). Application of foam or gel may have unknown or unintended consequences on glove integrity; however, during the Ebola outbreak in 2014, the Centers for Disease Control and Prevention (CDC) published detailed guidance (revised in 2015) recommending that ABHR be used for disinfecting the gloves at multiple times during doffing of the personal protective equipment. ${ }^{14} \mathrm{~A}$ recent paper demonstrated that multiple ethanol-based hand-rub administrations did not show observable signs of material degradation with nitrile and latex gloves ${ }^{15}$; however, the study did not test every available glove and was predominantly evaluating tensile strength and/or permeability, which may serve as an indicator of glove degradation. In addition, the authors reported that some types of glove material may become sticky to the touch after multiple administrations of $\mathrm{ABHR}$, but this was not considered problematic in clinical use. In the current, predominant approach to $\mathrm{HH}$, gloved hands are usually assumed to be contaminated, whereas bare hands are assumed to be clean (following appropriate washing or ABHR application). The application of ABHR to gloves could produce the unintended consequence of making the identification of clean hands more difficult (eg, "Are these gloves contaminated or was ABHR applied?"). Nevertheless, the authors believe that application of ABHR to gloves in the anesthesia workplace is worthy of consideration and further investigation. The CDC and WHO guidelines recommend removing gloves before performing $\mathrm{HH}$ as standard practice; however, given the frequency of $\mathrm{HH}$ opportunities in the perioperative setting, evaluation of the effectiveness and feasibility of application of ABHR to gloves in the anesthesia workplace as an alternative practice merits further investigation. Additionally, the authors encourage glove manufacturers to perform studies to indicate whether and how many ABHR applications can occur while still maintaining the glove's integrity.

\section{Environmental disinfection}

Should reusable laryngoscopes or video-laryngoscopes be replaced with single-use laryngoscopes/videolaryngoscopes?

Recommendation: The authors recommend that facilities ensure that standard direct laryngoscope or video-laryngoscope reusable handles and blades undergo high-level disinfection (at the minimum) or sterilization prior to use, or that reusable laryngoscopes are replaced with single-use standard direct laryngoscopes or video-laryngoscopes. Clean blades and handles should be stored in packaging appropriate for semicritical items designated for "high-level" disinfection.

Rationale: Researchers have found bacteria, blood, and lymphoid tissue contamination of laryngoscope blades and handles following low-level decontamination. ${ }^{16}$ Infectious disease outbreaks have been associated with contaminated laryngoscopes. ${ }^{17}$ Laryngoscopes are considered "semicritical" devices and therefore should be subjected to high-level decontamination (at the minimum) or sterilization. The Joint Commission and other regulators require that standard direct laryngoscope reusable blades be subject to high level decontamination (at the minimum) or sterilization and that blades be packaged to maintain decontamination until just prior to use. Optimal processing of laryngoscope handles has been subject to some controversy. Many reusable laryngoscope handles require disassembly prior to highlevel decontamination or sterilization, making the cleaning process potentially costly.

The authors recommend that handles that are not able to undergo high-level disinfection according to manufacturer's instructions should not be used. The State of California Health and Human Services Agency Department of Health Services recommends high-level decontamination of laryngoscope handles. $^{2}$ A study of laryngoscope handles cleaned with bactericidal wipes containing either $70 \%$ alcohol and $2 \%$ chlorhexidine or coco alkyl dimethyl benzyl ammonium chloride found that common bacteria were effectively eliminated; however, the authors point out that $C$. difficile and norovirus would not be expected to be eliminated by this treatment. ${ }^{19}$ They recommend autoclaving laryngoscope handles at risk for the presence of C. difficile and also on a routine, monthly basis.

Single-use laryngoscopes have evolved considerably in recent years. Their performance may be comparable to reusable laryngoscopes, and their cost per use may be less than reusable laryngoscopes if the costs of high-level decontamination of reusable laryngoscopes are considered. Environmental issues pertaining to single-use laryngoscopes are addressed by some manufacturers with recycling programs for their products.

Although the authors did not conduct a literature search specific to supraglottic airway masks, they note the plausibility of residual contamination of these masks and suggest that facilities consider applying the same principles when deciding between reusable and single-use supraglottic airway masks.

\section{Should anesthesia machines be partially or completely covered with disposable covers to prevent contamination?}

Recommendation: Current data are inadequate for the authors to make recommendations regarding the use of disposable covers to prevent contamination of anesthesia machines.

Rationale: Although several studies have demonstrated the potential for contamination of anesthesia equipment and workspaces and possible transmission of a variety of microorganisms within the anesthesia environment, the authors did not identify studies that evaluated the impact of equipment covers on the level of environmental contamination or patient infection risk. However, they suggest that facilities consider using disposable covers given the plausible reduction in contamination and facilitation of cleaning and disinfection of anesthesia machines. ${ }^{20-25}$

\footnotetext{
2"Items directly attached to instruments that contact mucous membranes, such as the handles of rigid laryngoscopes, should be considered semicritical instruments."18
} 


\section{When ORs are prepared between uses, what cleaning and disinfection of the anesthesia machine and anesthesia work area should take place?}

Recommendation: To reduce the bioburden of organisms and the risk of transmitting these organisms to patients, the facility should clean and disinfect high-touch surfaces on the anesthesia machine and anesthesia work area between OR uses with an EPA-approved hospital disinfectant that is compatible with the equipment and surfaces based on the manufacturers' instruction for use. Because of challenges in consistent cleaning and disinfection between cases of the anesthesia machine and anesthesia work area, the authors suggest prioritizing high-touch surfaces. In addition, the authors suggest evaluating strategies aimed at improving the ability to clean these surfaces (eg, disposable covers, re-engineering of work surfaces).

Rationale: A number of studies have demonstrated that anesthesia machines and work areas can become contaminated with a variety of potentially pathogenic microbes, and that these organisms may be transmitted to patients through direct contact with contaminated equipment, hands of anesthesia providers, or contaminated medications. ${ }^{20-25}$ However, few studies have evaluated specific cleaning and disinfection products or practices specific to the anesthesia work area.

The anesthesia work area, including the anesthesia machine, computer keyboard, monitor and mouse, reusable patient monitoring equipment, anesthesia cart, and ancillary equipment (such as ultrasound machines) are physically complex and are not primarily designed and engineered to facilitate efficient and thorough cleaning. The focus on expedited OR turnover within 10-15 minutes adds to the challenge of adequate cleaning. In the future, the authors encourage engineers and manufacturers to work with human factors experts to redesign the various components of the anesthesia work area to solve this problem. The authors suggest that anesthesia machine covers may be part of the solution, but evidence is lacking to endorse their use (see the preceding recommendation).

While awaiting evidence-based guidance, the authors recommend that the facility prioritize cleaning of the specific components that are most likely to be contaminated. Monitoring equipment such as reusable blood pressure cuffs, pulse oximeter probes, electrocardiogram (ECG) leads, twitch monitor leads and sensors, and cables that are in physical contact with patients should receive high priority for thorough cleaning (single-use monitoring sensors may be useful for reducing the cleaning burden). The anesthesia machine work surface, gas flow controls, vaporizer dials, adjustable pressure limiting valve (APL), IV stands and fluid warmers, supply cart, and computer keyboard and mouse, are also examples of components that are particularly likely to be contaminated.

\section{Should injection ports used by anesthesia providers in the OR be covered with isopropyl alcohol-containing caps? Should injection ports-without alcohol-containing caps-used by anesthesia providers in the OR be scrubbed with alcohol before each use?}

Recommendation: Anesthesia providers should only use disinfected ports for intravenous access. Ports may be disinfected either by scrubbing the port with a sterile alcohol-based disinfectant before each use immediately prior to each use or using sterile isopropyl alcohol containing caps that cover ports continuously. Prior to use, isopropyl alcohol-containing caps should cover the port for the minimum time recommended by the manufacturer. Ports should be properly disinfected prior to each individual drug injection or at the beginning of a rapid succession of injections, such as during induction of anesthesia. The authors recommend that providers consider using isopropyl alcohol containing caps, which, when in place for the recommended period, make ports immediately available for use at all times. Stopcocks should have closed injection ports installed to convert them into "closed ports," or they should be covered with sterile caps.

Rationale: Peripheral intravenous tubing stopcocks and injection ports that are used for medication administration frequently become contaminated with potentially pathogenic bacteria during intraoperative use. Lower rates of provider $\mathrm{HH}$, higher numbers of intravenous medications, and greater numbers of hub interactions increase the probability of injection port contamination. Although the literature does not provide direct evidence of clinical benefit in anesthesia practice, moderate- to high-quality evidence exists that disinfecting catheter hubs, needleless connectors, and injection ports with a sterile alcohol-containing disinfectant reduces the risk of central-line-associated bloodstream infection (CLABSI). ${ }^{26}$ Optimally, the authors recommend disinfection of injection ports to be performed before each medication injection, consistent with recommendations in other patient care settings; however, published studies do not address the optimal frequency of injection port disinfection and the comparative effectiveness of alcohol-containing caps and alcohol wipes in anesthesia practice, and the authors acknowledge that the act of disinfecting injection ports for 10-15 seconds followed by a drying time can be challenging in anesthesia practice, particularly during induction and emergence of anesthesia. ${ }^{27}$ For this reason, compared to alcohol wipes, passive disinfection using sterile alcohol-containing caps offers visual assurance of hub disinfection and may assist facilities in improving and monitoring compliance with this best practice. ${ }^{27}$

\section{When anesthesia drugs are drawn at the point of care should vials be scrubbed with alcohol prior to puncture?}

Recommendation: Anesthesia providers should wipe medication vials' rubber stoppers and necks of ampules with $70 \%$ alcohol prior to vial access and medication withdrawal.

Rationale: The caps of anesthesia medications are not sterile; therefore, it should be standard practice to disinfect the rubber stoppers and neck of ampules prior to each use. ${ }^{28}$ A study in New Zealand observed 10 anesthesia teams during 20 simulated cases. $^{29}$ None of the anesthesiologists disinfected the vial septa prior to drawing intravascular solutions, and the anesthesia teams said they believed this procedure was in compliance with infection prevention and control practices. These researchers isolated microorganisms from 5 of 38 collection bags (13\%), 6 of 17 needles $(35 \%)$, and 10 of 197 syringes $(5 \%){ }^{28-30}$

\section{Which intravenous catheters should be placed with full barrier precautions?}

Recommendation: All central venous catheters (CVCs) and axillary and femoral arterial lines should be placed with full maximal sterile barrier precautions. Full maximal sterile barrier precautions include wearing mask, cap, sterile gown, and sterile gloves and using a large sterile drape during insertion. Peripheral arterial lines (eg, radial, brachial, or dorsalis pedis arterial lines) should be 
placed with a minimum of a cap, mask, sterile gloves, and a small sterile fenestrated drape.

Rationale: The authors based this recommendation on the Compendium of Strategies to Prevent Bloodstream Infections in Acute Care Hospitals ${ }^{26}$ and the 2011 Healthcare Infection Control Practices Advisory Committee (HICPAC) guideline, ${ }^{31}$ which identify the following maximal sterile barrier precautions for CVC and axillary and femoral arterial line insertion:

1. All healthcare personnel involved in the catheter insertion procedure should wear mask, cap, sterile gown, and sterile gloves.

2. The provider should cover the patient with a large ("full body") sterile drape during catheter insertion.

The provider should also follow these measures when exchanging a catheter over a guidewire. Placement of other arterial lines should follow the HICPAC recommendations to use a minimum of a cover, mask, sterile gloves, and a small sterile fenestrated drape. ${ }^{31}$ As with other standard-of-care practices, in emergency situations providers should weigh other safety considerations.

Should providers always recap a medication syringe after giving a portion of the syringe contents to the patient if the syringe and medication may be used again on that patient?

Recommendation: To reduce the risk of bacterial contamination of the syringe and syringe contents, the authors recommend that anesthesia providers cap needleless syringes that will be used to administer multiple doses of a drug to the same patient after each administered dose. Needleless syringes should be capped with a sterile cap that completely covers the Luer connector on the syringe.

Rationale: Bacterial contamination of medication syringes can occur during anesthesia practice, most commonly with skin microorganisms. ${ }^{29}$ Higher rates of medication contamination have been associated with emergency procedures, compared to elective surgical procedures. Low provider $\mathrm{HH}$, lack of injection port disinfection, and contact with nonsterile equipment may increase the risk of intraoperative contamination of syringe contents when used to administer multiple doses of medication to the same patient. Although research has not assessed the effectiveness of capping medication syringes on reducing rates of medication contamination, it is plausible that capping medication syringes will reduce the risk of inadvertent contamination of the syringe and contents from the hands or work space of the anesthesia provider. The authors do not recommend recapping needles, which is highly discouraged due to the associated occupational hazards.

\section{What measures should be taken to protect clean supplies in the anesthesia cart from contamination? Should the anesthesia supply cart be cleaned between cases?}

Recommendation: The anesthesia supply cart should have its accessible outer surfaces wiped clean between cases. To prevent contamination of communal supplies, anesthesia providers should always perform HH before opening the drawers or bins of the cart and handling the contents of the drawers or bins. Storage of supplies on the top surface of the cart should be avoided as much as possible and any supply items on the cart top surface should be removed between cases to facilitate cleaning. The interior of the supply cart should be cleaned on a periodic basis. Future innovation and re-engineering of the storage, dispensing, and restocking of supplies in the anesthesia work area is needed to decrease the potential for bacterial cross contamination between cases.

Rationale: The anesthesia work area is contaminated with potential pathogens and poses a threat for clinically significant bacterial cross transmission. Hall ${ }^{32}$ confirmed the presence of blood contamination on $33 \%$ of surfaces, including surfaces in direct contact with the patient, for example, blood pressure cuffs and pulse oximeter probes after visual inspection of anesthesia work area surfaces. ${ }^{32}$ Research has found significant anesthesia work area bioburden with both commensal and pathogenic bacteria, including coagulase-negative staphylococci, Bacillus spp, streptococci, Staphylococcus aureus, Acinetobacter spp, and other gram-negative rods. ${ }^{20}$ Loftus et al ${ }^{33}$ studied the impact of bacterial contamination of patients, providers' hands, and stopcocks in the OR. They found that providers' hands and the surrounding environment were drivers of stopcock cross transmission, which was associated with increased patient 30-day mortality. Bacterial transmission in the anesthesia work area of the OR was associated with 30-day postoperative infections, which impact as many as $16 \%$ of patients undergoing surgery. ${ }^{34}$ Other studies have linked anesthesia provider hand contamination as a proximal source of both enterococcal and staphylococcal transmission in the anesthesia work area. ${ }^{23,25}$

Although studies quantifying the impact of contamination of anesthesia supply carts and work areas on surgical site infection (SSI) risks are lacking, a growing body of literature suggests potential contamination. ${ }^{20,33,35,36}$ Given the threat of bacterial cross transmission from the anesthesia work area, including the anesthesia machine and supply cart, the facility should take measures to minimize bioburden between all cases.

\section{What is the expiration time for sterile injectable drugs and intravenous solutions prepared by anesthesia providers?}

Recommendation: Provider-prepared sterile injectable drugs (eg, a drug drawn from a vial into a syringe) are more likely to be subject to contamination than drugs prepared in an ISO Class 5 setting, such as a pharmacy; therefore, provider-prepared sterile injectable drugs should be used as soon as practicable following preparation. The package inserts for propofol that contain a preservative typically specify that the use of propofol should commence within 12 hours of preparation. At the time of this publication, United States Pharmacopeia (USP) Chapter 797 recommends that the use of provider-prepared sterile injectable drugs commence within 1 hour of preparation; however, a draft revision of USP General Chapter 797 suggests that a drug from a single dose vial punctured or entered in environments with air less clean than ISO class 5 may be used until the end of a case. ${ }^{37}$ If available, commercially prefilled syringes or syringes prepared by the hospital pharmacy in an ISO class 5 setting have a relatively long "beyond use date."

Rationale: The USP 797 generally is considered the applicable authority for the compounding of sterile injectable solutions and drugs. At the time of this publication, USP 797 states that the use of compounded sterile provider-prepared products outside of an 
ISO class 5 setting (eg, a pharmacy IV room) be for "immediate use" only, commencing within 1 hour of preparation and interprets "compounding" as including drawing medications from vials into syringes. ${ }^{28}$ Scientific literature is sparse pertaining to a 1-hour limit on the advance preparation of sterile drugs for injection in an "immediate use" setting. To the best of our knowledge, the "1-hour limit" from USP 797 is based on the underlying principle that drugs prepared outside of a properly regulated pharmacy IV "clean room" are more likely to become contaminated, and bacterial counts may increase over time. ${ }^{38}$ Austin et $\mathrm{al}^{39}$ performed a systematic review of the literature and found a significantly higher frequency of contamination of doses prepared in clinical than in 10 pharmaceutical environments (3.7\% vs $0.5 \%$; $P=.007) .{ }^{39} \mathrm{~A}$ draft of the revision of USP Chapter 797 released in July 2018 contains language suggesting that provider prepared drugs could be used until "the end of a case."37 This draft is subject to change and will not be finalized until late in 2019.

Because no reliable method exists for knowing with certainty whether the drugs or solutions have been used, the authors suggest designated healthcare personnel discard provider-prepared sterile injectable drugs and intravenous solutions at the end of each case, whether used or not. If the drugs or solutions have been used, they may be contaminated and subsequent use for another patient may result in transmission of organisms to that patient. The facility may consider returning to stock unused commercial prefilled syringes, which have not passed their "beyond use" date, have intact security locking caps, and have been present in the anesthesia work area during a case; however, consideration should be given to the possibility that the external surface of such syringes may become contaminated during a case and pose an infection risk if reused for another case.

In addition to USP 797, the facility may consider the advice of other authorities, which may be at variance with the 1-hour limit recommended by USP 797. For example, The Joint Commission's recommendations for syringe labeling do not require labeling provider-prepared injectable drugs for "immediate use" with a date and time of expiration unless the expiration occurs within 24 hours of preparation, suggesting that "immediate use" may extend beyond 1 hour. The Food and Drug Administration (FDA) "package insert" for propofol states that propofol has a 12-hour expiration time after being drawn up into a syringe; formulations of propofol without preservative may have a 6-hour expiration time after being drawn up into a syringe. $^{40}$

\section{How long can IV bags be spiked in advance of commencing use?}

Recommendation: Anesthesia practitioners should minimize the time between spiking IV bags and patient administration; nevertheless, certain emergent or urgent circumstances may require advanced set-up of IV fluids and anesthesia providers should comply with their hospital protocols.

Following spiking of an IV bag, administration should commence as soon as possible. No specific time limit has been identified in the literature for advance preparation of IV bags. Rationale: Facilities should determine whether local regulatory authorities (eg, state boards of health or pharmacy) have rules regarding spiking of IV bags. Scientific literature pertaining to spiking IV bags is sparse. Haas et $\mathrm{al}^{41}$ found no bacterial growth up to 8 hours in 80 bags of lactated Ringer's solution spiked by a single provider following proper $\mathrm{HH}$, but they did not address whether these results are replicable across multiple providers, in other settings, and with other types of IV solutions.

Anesthesia providers occasionally spike IV fluids in advance, especially in preoperative holding areas and in ORs that are reserved for emergencies. Providers should weigh the risks versus benefits of spiking IV bags that are not intended for immediate use. The authors encourage facilities to conduct a risk assessment in collaboration with their Infection Prevention and Control Departments.

\section{Should syringes and medication vials be reused?}

Recommendation: Single-dose medication vials and flushes should be used whenever possible. If multiple-dose medication vials must be used, they should be used for only 1 patient and should only be accessed with a new sterile syringe and new sterile needle for each entry. Syringes and needles are single patient devices and syringes should never be reused for another patient, even if the needle is changed.

Rationale: The CDC established safe injection practices as part of its 2007 Guidelines for Isolation Precautions: Preventing Transmission of Infectious Agents in Healthcare Settings. ${ }^{42,43}$ Numerous authorities and organizations, including the Association for Professionals in Infection Control and Epidemiology (APIC), AANA, ASA, and the Joint Commission have issued guidelines and/or recommendations concerning injection safety and have referenced CDC safe injection practices. ${ }^{4-47}$ The Association of Anaesthetists of Great Britain and Ireland has also issued safe injection practices that mirror those of the CDC. ${ }^{48}$ The CDC recommendations are based on reports of outbreaks of preventable healthcare-acquired viral and bacterial infections resulting from improper injection safety practices. ${ }^{42}$ Improper injection safety practices include: use of single-dose medication vials for multiple patients, ${ }^{49-54}$ improper use of multiple-dose vials, ${ }^{50,55,56}$ and use of a single syringe or needle to administer intravenous medication to multiple patients. ${ }^{42,44,53,57}$ Several groups of researchers have reported outbreaks of preventable healthcare-acquired viral and bacterial infections in inpatient operating suites, adult and pediatric medical-surgical wards, and outpatient endoscopy, surgery, infusion, myocardial perfusion testing, and pain centers. ${ }^{49-53,55-60}$

\section{How should keyboards and touch screens in the anesthesia work area be cleaned and protected from contamination?}

Recommendation: Facilities should require cleaning and disinfection of computer keyboards and touchscreen computer monitors after each anesthesia case using a hospital-approved disinfectant consistent with manufacturers' recommendations. Additionally, cleaning and disinfection should also occur every time there is obvious soiling or contamination of anesthesia work surfaces. Facilities should consider use of commercial plastic keyboard shields, sealed medical keyboards, or washable keyboards and touchscreens to facilitate thorough disinfection.

Rationale: The problem of bacterial contamination of clinical and OR equipment is well documented as a host of bacteria such as coagulase-negative staphylococci, Bacillus spp, and even MRSA inhabit anesthesia surfaces, such as workspace computer 
touchscreens and keyboards. ${ }^{35}$ Research has identified the anesthesia computer mouse as one of the most contaminated surfaces in the OR, followed by the OR bed, nurse computer station mouse, the OR door, and the surfaces of the anesthesia medical work cart. ${ }^{36}$ Moist surfaces, such as damp gloves or computer keyboards, increase the risk of transmitting Staphylococcus epidermidis from one surface to another. ${ }^{61}$ Additional areas of concern include semi-sealed parts of anesthesia equipment, where bacteria may chronically colonize surfaces in areas not readily subject to cleaning procedures and where microbe growth may go undetected. $^{61}$

\section{What infection prevention and control modifications should be made, if any, for patients in contact isolation?}

Recommendation: Anesthesia providers should follow all institution-specific guidelines when caring for patients on contact isolation in the OR, including performing $\mathrm{HH}$ and using appropriate personal protective equipment (PPE). Environmental disinfection should follow recommendations regarding cleaning between cases, irrespective of an individual patient's multidrugresistant organism status.

Rationale: Data demonstrate that microorganisms, including multidrug-resistant organisms, can be spread via anesthesia providers in the OR. Research has shown contaminated hands of anesthesia providers contaminate the anesthesia work area, including the anesthesia machine, anesthesia cart, supplies on the cart, stopcocks and keyboards. ${ }^{23,34,62,63}$ In addition, up to $30 \%$ of organism transfer occurred between cases and was linked to an anesthesia work area that was not completely decontaminated with routine cleaning. ${ }^{34}$ The highest risk of contamination of the anesthesia work area occurs during induction and emergence of anesthesia. ${ }^{34,62} \mathrm{HH}$, contact precautions, and environmental disinfection recommendations to decrease transmission of pathogenic organisms outside of the OR also apply to providers in the OR environment.

\section{Implementation}

\section{Which techniques should be used to improve infection prevention practices by anesthesia providers?}

Recommendation: Facilities should conduct regular monitoring and evaluation of infection prevention practices. To promote adherence, improvement efforts should be collaborative and should include input from frontline anesthesia personnel and local champions. Hospital and physician leadership should identify clear expectations and goals, should ensure data transparency, and should facilitate use of process measures to improve performance.

Rationale: Although the authors did not identify studies that specifically addressed the efficacy of interventions to improve infection control among anesthesia providers, studies in anesthesia and elsewhere can inform an approach to implementing and sustaining improvements.

Improvement efforts should involve monitoring, evaluation, and feedback. Timely collection, analysis, and provision of data to providers are important, but they can be cumbersome and time consuming because collecting adherence data most often involves human observers. Overt observation of behaviors can improve practice, ${ }^{64}$ but it may be subject to the Hawthorne effect, in which the awareness of being observed changes one's behavior. ${ }^{65,66}$ Covert observations have been successful using video observation of anesthesia practices ${ }^{67,68}$ and procedural technique. ${ }^{69}$ Video recordings allow evaluation during all shifts and in many areas without overextending observing staff. ${ }^{67}$ Healthcare worker volunteers $^{52}$ and nonprovider volunteers ${ }^{70}$ have assessed $\mathrm{HH}$ practices on inpatient units.

Facilities providing feedback should focus on ways to improve adherence rather than place blame. Researchers have found that providers fail to adhere to infection prevention practices not out of malice or indifference but due to a complex combination of beliefs, work environment, technology, information load, and conditioning. ${ }^{71-75}$ Audit and feedback programs have been shown to be effective when designed using both theory and evidence. ${ }^{76}$ Institutions should be mindful that the hierarchical nature of team organization in the anesthesia work area could hinder honest communication and feedback. ${ }^{77}$ Fostering psychological safety and comfort in taking interpersonal risk may help workplace team learning and improvement. ${ }^{78}$

Clarity of expected behaviors in the context of a provider's role can help focus educational activities. ${ }^{79}$ Interventions such as reminder cards or checklists have been utilized to improve adherence to transmission-based precautions, ${ }^{80,81}$ as has simulation for education and evaluation of different aspects of anesthesia practice. ${ }^{29,82-84}$ A Children's Hospital Association working group developed an evaluation tool for infection prevention in anesthesia practice. While not validated empirically, facilities may consider use of this tool to initiate discussions among anesthesia providers and infection preventionists to identify areas of importance and in need of improvement. ${ }^{77}$

Leadership support helps to define goals, remove barriers, and hold practitioners accountable for their performance. ${ }^{85}$ One institution demonstrated sustained improvements in $\mathrm{HH}$ adherence following a 'stand-down' event following a $\mathrm{HH}$ summit attended by hospital leaders. This involved a hospital-wide 15minute period when all nonessential activity was stopped, plans to improve $\mathrm{HH}$ were discussed, and written action plans were submitted. Improvement efforts were supported by frequent covert observation and direct discussions of performance with institutional leaders. ${ }^{86}$ Although they are important to improving practices, institutions should be careful to not allow standards, monitoring, and incentives to have a negative effect on culture, learning, and interpersonal relationships. ${ }^{87}$

\section{What is the impact of providing measurement and feedback data on HH?}

Recommendation: Facilities should monitor providers' $\mathrm{HH}$ performance and give them feedback as part of a comprehensive program to improve and maintain adherence. Insufficient data exist to recommend the routine use of automated, electronic, or video monitoring and feedback, although examples in the literature demonstrate efficacy of such technology.

Rationale: Facilities have used various types of monitoring and feedback to increase providers' adherence to $\mathrm{HH}$. Because of the expense and the likelihood that measuring $\mathrm{HH}$ adherence through direct observation only provides a small sample of provider behavior, facilities' interest in automated measurements has increased, including video surveillance ${ }^{88}$ and a variety of electronic devices that detect and record providers' use of ABHR, to include such features as delivering real time reminders to perform 
HH. Systematic reviews of studies conducted outside of the OR concluded that insufficient information exists to recommend the use of automated monitoring and feedback, ${ }^{89,90}$ although a study of personal, wearable ABHR dispensers that emitted an audible alarm 6 minutes after the previous activation of the dispensers reported a 27-fold increase in $\mathrm{HH}$ compared to standard fixed ABHR dispensers. ${ }^{6}$ An intermittent reminder to perform $\mathrm{HH}$ displayed on a video screen in the anesthesia work area increased the hourly frequency of $\mathrm{HH}$ by approximately 10 -fold. $^{91}$

\section{What is the impact of providing measurement and feedback data on environmental disinfection?}

Recommendation: Facilities should utilize measures to assess the appropriateness and adequacy of environmental disinfection, track the measures, and share the results with stakeholders to optimize adherence to recommended disinfection practices.

Rationale: Measurement and feedback improve thoroughness of cleaning in inpatient settings ${ }^{54,92-100}$ via use of checklists of areas to clean, ${ }^{101}$ improvements to the cleaning methodology, including the cleanser used, ${ }^{97}$ and the use of visual indicators, such as ultraviolet visible markers ${ }^{93-97,99,100}$ and ATP bioluminescence. ${ }^{54,97}$ A study that focused on cross contamination of the work area by anesthesia providers reported improvements in anesthesia providers' adherence following engagement by coaching, as viewed through remote video observation. ${ }^{68}$ Multiple studies have demonstrated improved cleaning after sharing monitoring data with environmental service (EVS) staff, along with education, observation, and collaboration between infection prevention and EVS personnel. ${ }^{54,92-100}$ Some facilities improved adherence through capital investment in EVS, most often through the creation of a dedicated environmental disinfection team. $^{94,97,100}$

The authors recognize that these short-term responses may not be sustainable or generalizable to all contexts, and we did not identify studies that measured how feedback alone affects environmental disinfection. Nonetheless, the literature suggests improvements to adherence derive from the belief among environmental services personnel that adequate cleaning protects the health of patients and families, is expected, and is supported by the facility. ${ }^{102}$

\section{Background}

\section{Evidence for infectious sources in the anesthesia work area}

A growing body of literature suggests that the anesthesia work area can become contaminated with pathogens. ${ }^{20,23-25,32,34,35,103}$ Hall $^{32}$ confirmed the presence of blood contamination on $33 \%$ of surfaces that have direct contact with the patient (eg, blood pressure cuffs and pulse oximeter probes), and found that visual inspection of anesthesia work area surfaces was insensitive for detecting it. In 2001, Miller et $\mathrm{al}^{103}$ reported the presence of proteinaceous material, even after cleaning, on most laryngeal masks and laryngoscope blades. Maslyk et $\mathrm{al}^{20}$ identified a significant environmental bioburden with both commensal and pathogenic bacteria, including coagulase-negative Staphylococcus, Bacillus spp, Streptococcus, S. aureus, Acinetobacter and other gram-negative bacilli. With providers' use of double gloves for airway management, contamination of the anesthesia work area decreased but was not eliminated. ${ }^{104}$ Fukada et $\mathrm{al}^{35}$ reported significant contamination of the computer keyboard in the OR with commensals and pathogens such as $S$. aureus and MRSA due to anesthesia provider $\mathrm{HH}$ practice.

The intraoperative environment poses a threat for clinically significant bacterial cross transmission. Loftus et $\mathrm{al}^{33}$ studied the impact of bacterial contamination of patients, providers' hands, and the environment on stopcock contamination in the OR. Providers' hands and, in particular, the surrounding environment, were important drivers of stopcock cross transmission, which was associated with increased patient 30 -day mortality. ${ }^{105}$ In a subsequent study, Loftus et $\mathrm{al}^{34}$ demonstrated that bacterial transmission in the OR anesthesia work area was associated with 30 -day postoperative infections, impacting as many as $16 \%$ of patients undergoing surgery. Loftus et al found anesthesia provider hand contamination was a proximal source of both enterococcal and staphylococcal transmission in the anesthesia work area. $^{23,25}$ Birnbach et $\mathrm{al}^{63}$ reported a high degree of fluorescent marker spread following simulated airway management, including fluorescence on the face of a mannequin, the IV hub, and the keyboard, highlighting the potential for bacterial crosstransmission during anesthesia care.

A host of bacteria such as coagulase-negative staphylococci, Bacillus spp, and MRSA inhabit the anesthesia work area, including computer touchscreens and keyboards. ${ }^{35}$ The anesthesia computer mouse is one of the most contaminated surfaces in the OR, followed by the OR bed, nurse computer station mouse, the OR door, and the surfaces of the anesthesia medical work cart. $^{36}$ Moist surfaces, such as damp gloves or computer keyboards, increase the risk of transmitting $S$. epidermidis from one surface to another. ${ }^{35}$ Additional areas of concern include semisealed parts of anesthesia equipment and areas not readily subject to cleaning procedures, where bacteria may chronically colonize surfaces and microbial growth may go undetected. ${ }^{61}$

Medications used in anesthesia practice can become contaminated during use and support the growth of microorganisms, including bacteria and fungi. ${ }^{106}$ Mahida et $\mathrm{al}^{107}$ assessed the frequency of bacterial contamination of intravenous fluids and medications used in a sample from 101 surgical procedures performed at a single center. Of 426 used medication syringes (median, 4 per case), $15 \%$ of syringe tips and $4 \%$ of syringe contents grew bacteria, predominantly low colony counts of skin organisms (coagulase-negative Staphylococcus spp, Micrococcus, and Kocuria). Contamination of syringe contents was significantly more common during emergency than elective surgical procedures (odds ratio, $4.50 ; P=.01$ ), but the authors did not compare the frequency of medication administration or $\mathrm{HH}$ practices between emergency and elective procedures. As noted previously, Gargiulo et $\mathrm{al}^{29}$ found bacterial growth in 10 of 197 syringes (5\%), 5 of 17 needles (35\%), and 5 of 38 IV fluid bags $(13 \%)$ into which medications were injected, and gram-positive bacteria were most commonly isolated. The investigators observed that $\mathrm{HH}$ was never performed before entry into the simulation center or before drawing up medications, and that the septa of medication vials and IV injection ports were never disinfected with alcohol before they were used. They also observed nonsterile equipment, including stethoscopes and medical records, placed on top of uncapped, in-use medication syringes, but these researchers did not report the frequency with which it was observed. Although the literature search for this guidance did not identify a study that compares the impact of capping versus noncapping syringes used to administer multiple doses of medication on the frequency of bacterial contamination in simulation 
settings or clinical anesthesia practice, this same group of investigators found similar results in a follow-up study of actual patients in ORs. $^{29}$

A 1999 outbreak of Serratia marcescens among 7 postoperative patients was linked to a single anesthesiologist who drew up multiple propofol syringes at a time and did not use gloves for drawing up the syringes or for intubations. ${ }^{108}$ Behaviors cited during observations of other anesthesia personnel in this center included preparing multiple syringes of propofol at one time, using a single syringe for drawing up doses for different patients, using a single vial of propofol during a period of $>6$ hours and for more than a single patient, lack of compliance with glove usage, and failing to disinfect the rubber stopper of the medication vial before use.

Hilliard et $\mathrm{al}^{109}$ investigated flip-top drug vials and confirmed that the surface of the stopper of flip-top vials is frequently not sterile. Although this was an expected finding because stoppers of flip-top vials are not designed to be sterile and should be scrubbed with alcohol prior to access, in a survey of 878 anesthesiologists, $52 \%$ of respondents believed that the vial stoppers were sterile under the flip-top caps. ${ }^{109}$ A survey performed among anesthesia providers in New Zealand found that almost $80 \%$ of respondents said they rarely or never wiped the intravenous line injection port with alcohol before injection. Furthermore, 54\% of anesthesia providers failed to wipe the multi-dose vial septum with alcohol before use. $^{110}$

\section{Evidence for Infection Prevention Measures in the Anesthesia Work Area}

\section{Hand hygiene}

Epidemiology studies suggest that improved intraoperative $\mathrm{HH}$ is an important component of intraoperative infection prevention in the OR. ${ }^{111}$ The indications for the WHO 5 Moments include before and after direct contact with patients, after contact with body fluids or mucous membranes (eg, during endotracheal intubation), and after removal of gloves. ${ }^{112}$ Several studies have assessed opportunities for and compliance with the WHO 5 Moments recommendations during the provision of anesthesia care. ${ }^{2,113,114}$ Biddle et $\mathrm{al}^{2}$ performed an observational study of the $\mathrm{HH}$ of anesthesia providers using trained observers impersonating nurses to quantify $\mathrm{HH}$ practices during anesthesia delivery while minimizing the potential for observer influence. The overall failure to perform $\mathrm{HH}$ for all providers was $82 \%$. They found that during certain cases (eg, extensive blood loss, patients with particularly challenging airway issues, periods of high task density such as complicated emergence from anesthesia, and others) $\mathrm{HH}$ indications according to WHO reached 54 per hour.

Muñoz-Price et al found that anesthesia providers performed only $13 \mathrm{HH}$ events in 8 hours of observation. A subsequent study by Muñoz-Price et al reported that placing an ABHR dispenser on the anesthesia machine, in addition to standard wall-mounted dispensers, increased the rate of $\mathrm{HH}$ events from 0.5 to 0.8 events per hour $(p=01.01) .{ }^{4}$ ABHRs are able to achieve a $\sim 4-\log$ (99.99\%) reduction in microorganisms on providers' hands after a single application. ${ }^{115}$ Petty $^{5}$ suggests routine use of wearable ABHR dispenser to improve $\mathrm{HH}$ compliance among anesthesia staff. Koff et $\mathrm{al}^{6}$ studied wearable ABHR dispensers. During the control period, providers performed $\mathrm{HH}$ using either a wallmounted ABHR dispenser within 3 steps of the anesthesia work area or an ABHR dispenser on the anesthesia cart, and observers recorded the frequency of $\mathrm{HH}$ events. The intervention consisted of the use of personal, wearable ABHR dispensers with an audible reminder that alerted the provider if ABHR use had not occurred for 6 minutes. The personal, wearable device increased the frequency of $\mathrm{ABHR}$ use from 0.15 to 7.1 events per hour for attending physicians $(P=.008)$ and from 0.38 to 8.7 events per hour for other providers $(P=.002)$. The increase in $\mathrm{HH}$ was associated with reduction in contamination of the anesthesia work area and peripheral intravenous tubing. HAI rates decreased from $17.2 \%$ to $3.8 \%(P=.02)$. Notably, when the same group of investigators attempted to replicate their own results in a larger, multicenter study, use of the wearable dispensers was associated with an increased frequency of $\mathrm{HH}$ but not with a reduction in HAIs. ${ }^{7}$ Wearable dispensers were also associated with a reduction in ventilator-associated pneumonia in the ICU. ${ }^{116}$

Anesthesia providers in the OR are vulnerable to acquiring transient pathogenic microorganisms from hand contact with excretions, saliva, blood, or urine of hospitalized patients, and becoming vectors to transmit these organisms to others by direct touch. ${ }^{3,8,117}$ Gloves currently represent the most common barrier to prevent contamination and colonization of providers' hands during patient contact, but they require frequent changes during the anesthesia workday and $\mathrm{HH}$ after each removal.

The ASA Recommendations for Infection Control for the Practice of Anesthesiology, $3^{\text {rd }}$ edition, explicitly state that gloves should be worn whenever in contact with blood, body fluids, mucous membranes, or nonintact skin, and that gloves are not intended for reuse because removal of microorganisms and integrity cannot be ensured. ${ }^{47}$ Any time gloves are contaminated they should be removed and appropriate $\mathrm{HH}$ performed. In addition, the AANA Guidelines state that gloves should not be used with $>1$ patient. $^{46}$

\section{Injection of intravenous drugs}

Peripheral intravenous tubing stopcocks and injection ports that are used for medication administration frequently become contaminated with bacteria during intraoperative use. Bacterial contamination was detected in $>30 \%$ of intraluminal surface samples of stopcocks cultured at the end of general anesthesia cases, ${ }^{22,23}$ and included common skin contaminants (eg, coagulase-negative staphylococci, Micrococcus) as well as multidrug-resistant organisms (eg, MRSA, vancomycin-resistant enterococcus, Acinetobacter). Several potential reservoirs within the OR have been associated with intravenous tubing stopcock contamination.

Anesthesia providers report low overall rates of compliance with national recommended practices for injection port disinfection. Only 20.9\% of New Zealand anesthetists reported "always" or "frequently" wiping the IV line with alcohol before injection in the OR although $31.6 \%$ responded "never" to this question. ${ }^{110}$ Similarly, $40 \%$ of anesthesia service managers in Australia reported "never disinfecting" arterial line access ports with $70 \%$ alcohol or povidone iodine before use. ${ }^{118}$

In a prospective observational study of 548 adult patients undergoing surgery requiring general anesthesia, Loftus et $\mathrm{al}^{33}$ found that $23 \%$ of stopcock samples became contaminated intraoperatively. Stopcock contamination was more often attributed to bacterial strains contaminating the anesthesia machine's adjustable pressure-limiting valve than to strains on anesthesia providers' hands or colonizing the patient's nasopharynx and axilla. Bacterial contamination rates of IV tubing stopcock 
extensions were similar after 6 hours of incubation following removal at the end of procedures. Intraoperative stopcock contamination was associated with a lower hourly rate of $\mathrm{HH}$ compliance by anesthesia providers resulting in increased risk of 30-day mortality for patients but not with increased risk of postoperative HAIs. The article did not report the method and frequency of stopcock hub disinfection or medication injection practices.

In a prospective study of same-day ambulatory surgery procedures, bacterial contamination rates of IV tubing stopcock extension sets were similar after 6 hours of incubation following removal at the end of procedures performed with $(17.3 \%)$ and without (18.6\%) administration of ethylenediaminetetraacetic acid (EDTA)-containing propofol anesthetic. ${ }^{106}$ Procedures with propofol anesthesia were longer (1-2 hours versus $<1$ hour) and associated with a greater number of administered medications and hub interactions than nonpropofol procedures. When IV extension set sampling was repeated after 24 hours and 48 hours hold time, presence of visible propofol in the dead spaces of stopcocks was associated with a significant increase in bacterial colony counts compared with the extension set with no visible propofol or sets with no use of propofol, suggesting that even preservative-containing propofol may promote bacterial growth in IV stopcock and tubing associated with prolonged durations of administration. The authors did not report compliance with stopcock injection port disinfection or provider intraoperative $\mathrm{HH}$.

In a prospective, single-blinded controlled trial at a single center, Loftus et $\mathrm{al}^{119}$ randomized 592 ORs to use either conventional open stopcocks or conventional open stopcocks that were disinfected with an alcohol containing scrub device. Disinfection of the open stopcocks significantly reduced bacterial contamination of the stopcock lumen ( $32 \%$ vs $41 \%$; adjusted odds ratio, $0.703 ; P=.047)$; however, the rate of contamination was high in both groups. More than half the bacterial isolates identified in stopcock lumens or aspirated lumen effluent were coagulase-negative staphylococci (52\%), S. aureus (1\%), Pseudomonas aeruginosa (1\%), and other gram-negative bacilli (1\%).

In another prospective, single-blinded controlled trial at the same center, Loftus et $\mathrm{al}^{105}$ randomized 468 ORs and anesthesia providers to 1 of 3 medication injection schemes: (1) a closed stopcock device that was disinfected with $70 \%$ isopropyl alcohol before injection, (2) the same closed stopcock device not disinfected before injection, and (3) usual practice with conventional open-lumen stopcocks. The port disinfection arm required the use of $70 \%$ alcohol for disinfection and 30 seconds drying between each injection, but the study did not control for the technique (scrubbing vs wiping) or alcohol source (pump dispenser vs pad). Following induction of anesthesia, the rate of bacterial contamination of the closed stopcock with alcohol disinfection was $0 \%$, while the closed stopcock device with no disinfection before injection was $4 \%$, and the open stopcock system was 3.2\%, suggesting that the benefit of a closed stopcock device derives primarily from the ability to disinfect the injection port prior to drug injection.

In a quasi-experimental quality improvement project at a pediatric teaching hospital, Martin et $\mathrm{al}^{68}$ assessed the impact of a bundle of interventions on reducing rates of CLABSI among patients that travelled out of the ICU for anesthesiology care in ORs or procedure areas. The intervention included recommendations and anesthesia provider education to limit touch contamination during airway management, peripheral IV insertion, and anesthesia cart contact. In addition, providers were instructed to perform a single 15-second scrub with alcohol and 15-second drying time of the IV injection ports at the start of each case before attaching medication syringes to the series of 3-way stopcocks. All medications administered via this stopcock set were considered clean, although the study does not report provider $\mathrm{HH}$ before medication administration. CLABSI rates decreased from a baseline of 14.1 per 100 trips from the ICU to 9.7 in year 1 and to zero in year 2. During this same period, hospital-wide CLABSI rates decreased from 3.5 to 2.2 per 1,000 device days, suggesting that other interventions outside of modifications in anesthesia practice likely contributed to the observed reduction in CLABSI rates among ICU patients who received anesthesia care.

Cole et al ${ }^{106}$ cultured stopcocks used for propofol and nonpropofol anesthesia. Bacteria were recovered from 26 of 150 propofol anesthesia stopcocks $(17.3 \%)$ and 28 of 150 nonpropofol stopcocks (18.6\%). As expected, mean bacterial colony counts were much higher at 24 hours for propofol stopcocks, whether or not propofol was visible (nonpropofol 95 colonyforming units $[\mathrm{CFU}] / \mathrm{mL}$, nonvisible propofol $418 \mathrm{CFU} / \mathrm{mL}$, visible propofol 2,361 CFU/mL), suggesting that safe injection practices may not consistently occur. ${ }^{106}$

\section{Environmental cleaning}

The bioburden of the anesthesia work area and potential crosstransmission dynamics pose a threat to patient safety. Practices for the cleaning, handling, and processing of anesthesia equipment have been published by the Association of erioperative Registered Nurses (AORN). ${ }^{120}$ Martin et $\mathrm{al}^{68}$ reported a significant reduction of CLABSIs by improving practices in the OR including $\mathrm{HH}$, strategic gloving, and standardized cleaning of the anesthesia cart, IV pole, stopcock clamp, anesthesia machine, computer, monitor, knobs, surfaces, and laryngoscope handle). Clark et $\mathrm{al}^{121}$ trained a group of anesthesia providers to keep the anesthesia equipment cart clean, placed a placard on the cart top stating "clean hands only," designated the surface of the anesthesia machine for materials used during the case, and placed a separate container on the anesthesia machine for contaminated items. Known contaminated sites were wiped with an ammonium chloride-based wipe. After enacting these interventions, colony counts substantially declined on the adjustable pressure limiting valve, the oxygen control knob, the anesthetic agent control dial, and drawer pulls to the first and second drawers in the anesthesia equipment cart. ${ }^{121}$

Although several studies identified by the literature search demonstrated contamination of anesthesia equipment and workspaces, as well as possible transmission of a variety of microorganisms within the anesthesia environment, the search did not identify studies that evaluated the impact of equipment covers on the level of environmental contamination or on risk of patient infection. Maslyk et $\mathrm{al}^{20}$ swabbed anesthesia machine tabletops located in randomly selected ORs and detected Acinetobacter and other gram-negative bacilli, S. aureus, and coagulase-negative staphylococci, both before and after devices were used, despite routine cleaning. Baillie et $\mathrm{al}^{21}$ obtained swabs from surfaces of anesthetic and monitoring equipment that were not in contact with patients but were routinely touched by anesthesia providers during surgical procedures, including oxygen, nitrous oxide and air flow control knobs, vaporizer dials, 
breathing system bags, adjustable pressure-limiting valves, and monitoring control buttons. They detected the same types of bacteria as Maslyk et al.

Loftus et al assessed ${ }^{22}$ transmission of potentially pathogenic bacteria in the anesthesia work area by culturing intravenous stopcock sets and adjustable pressure-limiting valve complex and agent dials prior to the start of surgical procedures and after completion of the case. They noted a significant increase in the number of bacterial colonies per surface area sampled at case conclusion and found bacterial contamination of intravenous stopcock sets in $32 \%$ of cases, as well as an association between the risk of stopcock contamination and degree of anesthesia work space contamination. In a series of follow-up studies, they evaluated the dynamics of transmission of enterococci, S. aureus, and gram-negative organisms by comparing isolates found on patient screening cultures, anesthesia providers' hands, and the adjustable pressure-limiting valves and agent dials of the anesthesia machines during the first and second operative cases (case pairs) performed on a given day at 3 academic medical centers. Isolate relatedness was based on species, antimicrobial susceptibility results, and temporal association. ${ }^{23-25,34}$ For all 3 organism types, possible transmission events were common and appeared to involve both environmental and anesthesia provider hand contamination reservoirs. Mahida et $\mathrm{al}^{107}$ performed swab cultures of the external surface of syringe tips and syringe contents in addition to surface swabs of ventilator machines and found that the same bacterial species was cultured from both the ventilator and the syringe tip in $13 \%$ of cases, as well as in the intravenous fluid administration set in $4 \%$ of cases, suggesting the potential for environmental contamination leading to contamination of intravenously administered medications. ${ }^{107}$

Gonzalez et $\mathrm{al}^{122}$ compared different disinfectant wipes, finding S. aureus, Bacillus atrophaeus spores, and Clostridium sporogenes spores on the surface of an anesthesia machine, sterile flat caps, and ridged caps (used to simulate the actual knobs on anesthesia machines) and cleaned with 5 commercially available disinfectant wipes containing: (1) diisobutylphenoxyethoxyethyl dimethyl benzyl ammonium chloride, (2) citric acid, (3) sodium hypochlorite, (4) hydrogen peroxide, and (5) o-phenylphenol/obenzyl-p-chlorophenol as well as sterile gauze soaked in water or $5 \%$ bleach diluted 1:10 in water. ${ }^{122}$ All wipes cleaned the surfaces significantly better than the no-wipe control. Removal of $S$. aureus from the machine surface by the commercial wipes was not better than gauze with bleach and water but outperformed gauze and water when cleaning the flat and ridged caps. Bacillus atrophaeus and $C$. sporogenes spores were more difficult to clean from the machine surface and caps compared to $S$. aureus. Gauze with bleach and water removed $99 \%$ of spores from the machine's surface, and only the sodium hypochlorite wipe significantly outperformed gauze and bleach and water. No commercial disinfectant wipe performed significantly better than gauze and bleach water when cleaning spores from the caps. Gonzalez et $\mathrm{al}^{122}$ found that all 3 organism types maintained viability after being dried on these surfaces after a month. The investigators concluded that these results emphasized the importance of physical removal of bacteria from anesthesia device surfaces between uses.

Rutala et $\mathrm{al}^{123}$ found that novel touchless disinfection technologies (eg, ultraviolet-C light and hydrogen peroxide cleaning systems) are effective in further reducing bioburden after a standard cleaning and may be considered by facilities for terminal cleaning of ORs. However, the clinical efficacy on reduction of device-associated infections and SSIs has not been studied, and the intervention has not been subjected to a cost-benefit analysis. $^{123}$

\section{Airway management}

Although few articles have been published reporting outbreaks directly linked to contaminated laryngoscopes, ${ }^{124,125}$ multiple studies have demonstrated the high frequency with which blood and bacteria can be found on both laryngoscope blades and handles, even after reprocessing. ${ }^{16,126-129}$ One study found viable bacterial contamination in up to $57 \%$ of blades and $86 \%$ of handles from laryngoscopes that were disinfected and ready for use on the next patient. ${ }^{16}$ Bhatt et al $^{130}$ also found bacterial contamination of flexible fiber-optic laryngoscopes. Several studies have noted the theoretical risk of transmitting CreutzfeldtJakob Disease (CJD) from contaminated reusable laryngoscopes. CJD proteins have been identified in lymphoid tissue from patients with variant CJD (vCJD) but not other prion diseases, ${ }^{131}$ and Hirsch et $\mathrm{al}^{132}$ found that $30 \%$ of laryngoscope blades contained lymphocytes after a single use. Although there are no published reports of prion transmission via laryngoscopy, the long latency period between exposure and onset of disease makes identification of transmissions difficult. Based on the potential, though unproven, risk of vCJD transmission and the extreme difficulty of eradicating prion proteins from equipment, the authors suggest that facilities consider single-use laryngoscope blades. ${ }^{131,132}$

The literature search identified a number of studies that compare the cost and function of single-use laryngoscopes or video-laryngoscopes, but no studies were identified that used clinical infection outcomes. Using direct patient care and simulated patient studies, the search identified $>30$ articles that compared devices based largely on indirect patient related outcomes, such as user experience, ease of visualization of larynx during intubation, efficiency of use during rapid sequence intubation, duration of laryngoscopy, peak force applied to tissues, and quality of light. The various studies compared different products and used different outcomes. Overall providers showed a preference toward reusable direct laryngoscopes/video-laryngoscopes over the single-use devices; however, older studies do not reflect the current state of single-use laryngoscope technology.

The authors identified unpublished, anecdotal reports from a number of hospitals that switched from reusable to single-use laryngoscopes. These facilities cited lower cost of new generation single-use laryngoscopes compared to previously tested models, especially when the cost of high-level disinfection or sterilization of reusable laryngoscope handles was included. Additionally, the function of single-use laryngoscopes was reportedly improved compared to earlier models and compared favorably with reusable equipment, especially considering that reusable laryngoscope function may degrade over time due to wear and tear. In addition, single-use laryngoscope batteries hypothetically are fresh, whereas reusable laryngoscope batteries discharge variably with repeated use.

Anesthesia providers' hands may become contaminated with upper-airway secretions while providing airway management and endotracheal intubation resulting in cross contamination of the anesthetizing area. ${ }^{3,8,9,117}$ Two studies were identified in the literature search related to "double gloving" during airway management. ${ }^{8,9}$ In these studies, conducted in a simulation setting, a 
fluorescent marker identified the hypothetical spread of material from the patient's airway to the surrounding environment. Wearing double gloves and immediately discarding the outer gloves following airway management led to reduction in contamination of the environment. Contamination was further reduced when the laryngoscope was "sheathed" with an outer glove as it was removed.

\section{Future Directions}

The authors identified several unique elements of anesthesia practice that pose unsolved problems for infection prevention. These include the anesthesia machine, the anesthesia cart, and provider prepared drugs and IV infusion bags.

Numerous challenges exist for thorough cleaning of the anesthesia machine between cases. The anesthesia machine is a complicated apparatus with an irregular and complex external surface. Many anesthesia machines also have drawers to store supplies. Anesthesia machines were designed at a time when the importance of infection prevention in the anesthesia workplace was not well understood, and since then, the fundamental design has not changed greatly. The anesthesia machine may need to undergo fundamental redesign that allows for quick and effective cleaning of the external surfaces.

The anesthesia supply cart presents similar challenges and cleaning the anesthesia cart between cases can be extremely challenging depending upon the particular design of the cart. Anesthesia carts have many variations, which also can have a complex exterior surface due to attachment of electrical components such as a defibrillator or cardiac output monitor, sharps collection containers, waste bins, and discarded drug collection containers. Supplies and materials may be stored in cart drawers but also in bins on the top of the cart. Typical anesthesia carts contain supplies and materials intended to be used for numerous cases. Contamination of supplies can occur if providers do not remove soiled exam gloves and apply ABHR prior to obtaining supplies and materials from storage. Few examples exist of practices that have attempted to include the anesthesia cart in a "clean zone," where only clean hands are allowed. Although some success has been documented with this approach, maintaining the desired provider behavior presents challenges.

Anesthesia providers are frequently engaged in preparing sterile drugs for injection by bolus and infusion. Provider prepared drugs are not prepared using the same stringent methods as pharmacies and commercial compounders, increasing the possibility for contamination. Because bacteria may multiply over time, common sense suggests that providers should commence administration of provider prepared drugs promptly; however, little evidence exists concerning the length of time that is safe. Minimizing the use of provider-prepared drugs by using drugs that are prepared in a pharmacy or by a commercial compounder is a possible or partial solution. Some of the recommendations provided in this guidance might need to be reinterpreted if a new version of USP $797^{28}$ is available (scheduled for release in late 2019).

The authors encourage investment in research to better understand the infection prevention and control problems posed by the anesthesia work station and to develop design improvements that reduce the risk of infection.
Acknowledgments. The authors thank Randall M. Clark, MD, Chair, American Society of Anesthesiologists (ASA) Section on Clinical Care, Denver, Colorado, for extensively reviewing and vetting the guidance, as well as review and feedback by ASA workgroup members: Lois A. Connolly, MD, Chair, ASA Committee on Quality Management and Departmental Administration, Waukesha, Wisconsin; Elizabeth Rebello, MD, US Pharmacopeia Representative, ASA Committee on Quality Management and Departmental Administration, Houston, TX; Mary Ann Vann, MD, Chair, ASA Committee on Occupational Health, Medfield, MA; Richard A. Beers, MD, Advisory Group on Infectious Disease, ASA Committee on Occupational Health, Syracuse, NY; Matthew T. Popovich, PhD, Director of Quality and Regulatory Affairs, ASA, Washington, DC. The authors thank Charles Griffis, PhD, CRNA, Lynn Reede, DNP, MBA, CRNA, and Victoria Hledin, MPH, who reviewed the document on behalf of the American Association of Nurse Anesthetists (AANA). The authors thank Susan A. Dolan, RN, MS, CIC, Hospital Epidemiologist at the Children's Hospital Colorado, Colorado Springs, Colorado, for serving as an expert reviewer of the guidance. The authors thank Valerie Deloney, MBA, for her organizational expertise and assistance in the development of this manuscript.

Financial support. This expert guidance was supported in part by the SHEA Research Network (SRN).

Conflicts of Interest. The following disclosures reflect what has been reported to SHEA. To provide thorough transparency, SHEA requires full disclosure of all relationships, regardless of relevancy to the guideline topic. Evaluation of such relationships as potential conflicts of interest is determined by a review process which includes assessment by the SHEA Guidelines Chair, the SHEA Conflict of Interest Committee, and may include the Board of Trustees and Editor of Infection Control and Hospital Epidemiology. The assessment of disclosed relationships for possible COI is based on the relative weight of the financial relationship (ie, monetary amount) and the relevance of the relationship (ie, the degree to which an association might reasonably be interpreted by an independent observer as related to the topic or recommendation of consideration). The reader of this guidance should be mindful of this when reviewing the list of disclosures.

D.B. reports activity with APSF (Board of Directors) and Anesthesia and Analgesia (A\&A) Editorial Board. R.M. reports research grants/contracts with Medimmune, Johns Hopkins (lead in multicenter trial) HAI Among Surgical \& ICU Patients. B.C. reports research grants/contracts with Pfizer, Merck, CDC, Preventing Hemodialysis Related BSI. E.P.D. reports research grants/ contracts with Tetraphase, A Phase 3 Randomized Double-Blind DoubleDummy Multicenter Prospective Study to Assess the Efficacy \& Safety of Eravacycline vs Ertapenem in Intra-Abdominal Infections, advisory/ consultant roles with Merck, Baxter, Ortho-McNeil, Targanta, ScheringPlough, Astellas, CareFusion, Durata, Pfizer, Rib-X, institutional benefit with Exoxemis, UW letter to FDA supporting research proposal $<\$ 10,000$, activities with SIS (Board Member), ICHE (Editorial Board), CDC/HICPAC (content expert for SSI guideline), SCIP. G.H.P. reports research grants/ contracts with UT, Decreasing Vancomycin Use in the NICU. B.L.J. reports research grants/contracts with Gilead Sciences Inc., A Multicenter Randomized Double-Blind Double-Dummy Phase 3 Study of the Safety \& Efficacy of Ritonavir-Boosted Elvitegravir (EVG/r) vs. Raltegravir (RAL) Administered with a Background Regimen in HIV-1 Infected, Antiretroviral Treatment-expe, CHUM, The Canadian Cohort of Slow Progressors (HIV), Pfizer Canada, An International Multicenter Prospective Observational Study of the Safety of Maraviroc Used with Optimized Background Therapy in Treatment-experienced HIV-1 Infected Patients, Ottawa Hospital, A Randomized Control Clinical Trial of Micronutrient \& Antioxidant Supplementation in Persons with Untreated HIV Infection, MAINTAIN Study CTN 238 \& CTN 254: Inflammatory Markers Sub-Study, Canadian HIV Trials Network, VALIDATE, Capital Health Research FundFrailty in people living with HIV, PHAC CNISP: Surveillance for HA-CVC-BSI, CDI, PJI (hip \& knee), VP shunt infection, MRSA, VRE, \& CRE, and institutional benefit through Pfizer Canada, GSK, Sunovion Pharmaceuticals Canada (unrestricted 
grant), Capital District Health Authority Foundation, Infectious Diseases CME for Family Physicians (October 2013), $<\$ 10,000$, Optimer Pharmaceuticals Canada, Merck Canada, ViiV Healthcare Canada, BMS Canada, Gilead Sciences (unrestricted grant), Atlantic Canada HIV Education (September 2012), >\$25,000, and activity with PHAC Working Group for IC (Chair of Guidelines for HCW Infected with a Bloodborne Pathogen), CJIDMM (Associate Editor), IDSA (influenza guideline panel, SHEA), CPSNS (Chair), ad hoc Committee on BBP. D.P. reports activity with Extended National Faculty (SHEA faculty stipend for HRET/AHA CUSP). R.P. reports activity with APSF (Board of Directors) and Anesthesia and Analgesia (A\&A) Editorial Board. All other authors report nothing to disclose.

Supplementary material. To view supplementary material for this article, please visit https://doi.org/10.1017/ice.2018.303

\section{References}

1. SHEA. The Society for Healthcare Epidemiology of America (SHEA) Handbook for SHEA-Sponsored Guidelines and Expert Guidance Documents, 2017. http://www.shea-online.org/images/docs/ 2017_Handbook.pdf. Published 2017. Accessed January 2017.

2. Biddle C, Shah J. Quantification of anesthesia providers' hand hygiene in a busy metropolitan operating room: what would Semmelweis think? Am J Infect Control 2012;40:756-759.

3. Munoz-Price LS, Riley B, Banks S, Eber S, Arheart K, Lubarsky DA, et al. Frequency of interactions and hand disinfections among anesthesiologists while providing anesthesia care in the operating room: induction versus maintenance. Infect Control Hosp Epidemiol 2014;35:1056-1059.

4. Munoz-Price LS, Patel Z, Banks S, Arheart K, Eber S, Lubarsky DA, et al. Randomized crossover study evaluating the effect of a hand sanitizer dispenser on the frequency of hand hygiene among anesthesiology staff in the operating room. Infect Control Hosp Epidemiol 2014;35:717-720.

5. Petty WC. Closing the hand hygiene gap in the postanesthesia care unit: a body-worn alcohol-based dispenser. J Perianesth Nurs 2013;28:87-93.

6. Koff MD, Loftus RW, Burchman CC, et al. Reduction in intraoperative bacterial contamination of peripheral intravenous tubing through the use of a novel device. Anesthesiology 2009;110:978-985.

7. Koff MD, Brown JR, Marshall EJ, et al. Frequency of hand decontamination of intraoperative providers and reduction of postoperative healthcare-associated infections: a randomized clinical trial of a novel hand hygiene system. Infect Control Hosp Epidemiol 2016;37:888-895.

8. Birnbach DJ, Rosen LF, Fitzpatrick M, Carling P, Arheart KL, MunozPrice LS. Double gloves: a randomized trial to evaluate a simple strategy to reduce contamination in the operating room. Anesth Analg 2015;120:848-852.

9. Birnbach DJ, Rosen LF, Fitzpatrick M, Carling P, Arheart KL, MunozPrice LS. A new approach to pathogen containment in the operating room: sheathing the laryngoscope after intubation. Anesth Analg 2015;121:1209-1214.

10. Gadalla F, Fong J. Improved infection control in the operating room. Anesthesiology 1990;73:1295.

11. National Fire Protection Association. NFPA 101: Life Safety Code. NFPA catalog website. https://catalog.nfpa.org/NFPA-101-C3317.aspx. Published 2012. Accessed October 24, 2018.

12. Boyce JM, Pearson ML. Low frequency of fires from alcohol-based hand rub dispensers in healthcare facilities. Infect Control Hosp Epidemiol 2003;24:618-619.

13. Kramer A, Kampf G. Hand rub-associated fire incidents during 25,038 hospital-years in Germany. Infect Control Hosp Epidemiol 2007;28:745-746.

14. Guidance on personal protective equipment (PPE) to be used by healthcare workers during management of patients with confirmed ebola or persons under investigation (PUIs) for Ebola who are clinically unstable or have bleeding, vomiting, or diarrhea in US hospitals, including procedures for donning and doffing PPE 2015. Centers for Disease Control and Prevention website. https://www.cdc.gov/vhf/ebola/healthcare-us/ppe/guidance.html. Published 2015. Accessed October 25, 2018.
15. Gao P, Horvatin M, Niezgoda G, Weible R, Shaffer R. Effect of multiple alcohol-based hand rub applications on the tensile properties of thirteen brands of medical exam nitrile and latex gloves. J Occup Environ Hyg 2016;13:905-914.

16. Lowman W, Venter L, Scribante J. Bacterial contamination of re-usable laryngoscope blades during the course of daily anaesthetic practice. $S$ Afr Med J 2013;103:386-389.

17. Muscarella LF. Reassessment of the risk of healthcare-acquired infection during rigid laryngoscopy. J Hosp Infect 2008;68:101-107.

18. Inadequate reprocessing of semicritical instruments: recommendations for reprocessing of rigid laryngoscopes. California Department of Health and Human Services website. www.cdph.ca.gov/pubsforms/guidelines/ documents/inadequatereprocessingofrigidlaryngoscopes.pdf. Published 2007. Accessed October 25, 2018.

19. Howell V, Thoppil A, Young H, Sharma S, Blunt M, Young P. Chlorhexidine to maintain cleanliness of laryngoscope handles: an audit and laboratory study. Eur J Anaesthesiol 2013;30:216-221.

20. Maslyk PA, Nafziger DA, Burns SM, Bowers PR. Microbial growth on the anesthesia machine. AANA J 2002;70:53-56.

21. Baillie JK, Sultan P, Graveling E, Forrest C, Lafong C. Contamination of anaesthetic machines with pathogenic organisms. Anaesthesia 2007;62:1257-1261.

22. Loftus RW, Koff MD, Burchman CC, et al. Transmission of pathogenic bacterial organisms in the anesthesia work area. Anesthesiology 2008;109:399-407.

23. Loftus RW, Koff MD, Brown JR, et al. The epidemiology of Staphylococcus aureus transmission in the anesthesia work area. Anesth Analg 2015;120:807-818.

24. Loftus RW, Brown JR, Patel HM, et al. Transmission dynamics of gramnegative bacterial pathogens in the anesthesia work area. Anesth Analg 2015;120:819-826.

25. Loftus RW, Koff MD, Brown JR, et al. The dynamics of Enterococcus transmission from bacterial reservoirs commonly encountered by anesthesia providers. Anesth Analg 2015;120:827-836.

26. Yokoe DS, Anderson DJ, Berenholtz SM, et al. A compendium of strategies to prevent healthcare-associated infections in acute care hospitals: 2014 updates. Infect Control Hosp Epidemiol 2014;35:967-977.

27. Moureau NL, Flynn J. Disinfection of needleless connector hubs: clinical evidence systematic review. Nurs Res Pract 2015:796762.

28. United States Pharmacopeia (USP) and the National Formulary (NF) General Chapter $<797>$ Pharmaceutical Compounding. Sterile Preparations. USP website. http://www.usp.org/compounding/generalchapter-797. Published 2008. Accessed October 24, 2018.

29. Gargiulo DA, Sheridan J, Webster CS, et al. Anaesthetic drug administration as a potential contributor to healthcare-associated infections: a prospective simulation-based evaluation of aseptic techniques in the administration of anaesthetic drugs. BMJ Qual Saf 2012;21:826-834

30. Hemingway CJ, Malhotra S, Almeida M, Azadian B, Yentis SM. The effect of alcohol swabs and filter straws on reducing contamination of glass ampoules used for neuroaxial injections. Anaesthesia 2007;62:286-288.

31. O'Grady NP, Alexander M, Burns LA, et al. Summary of recommendations: Guidelines for the Prevention of Intravascular Catheter-related Infections. Clin Infect Dis 2011;52:1087-1099.

32. Hall JR. Blood contamination of anesthesia equipment and monitoring equipment. Anesth Analg 1994;78:1136-1139.

33. Loftus RW, Brown JR, Koff MD, et al. Multiple reservoirs contribute to intraoperative bacterial transmission. Anesth Analg 2012;114:1236-1248.

34. Loftus RW, Koff MD, Birnbach DJ. The dynamics and implications of bacterial transmission events arising from the anesthesia work area. Anesth Analg 2015;120:853-860.

35. Fukada T, Iwakiri H, Ozaki M. Anaesthetists' role in computer keyboard contamination in an operating room. J Hosp Infect 2008;70:148-153.

36. Link T, Kleiner C, Mancuso MP, Dziadkowiec O, Halverson-Carpenter K. Determining high touch areas in the operating room with levels of contamination. Am J Infect Control 2016;44:1350-1355. 
37. United States Pharmacopeia (USP). Proposed Revision to General Chapter 797: Pharmaceutical Compounding-Sterile Preparations 2018. July 27 proposed revision for public comment. USP website. http://www. usp.org/compounding/797-download. Updated July 27, 2018. Accessed October 24, 2018.

38. Fukada T, Ozaki M. Microbial growth in propofol formulations with disodium edetate and the influence of venous access system dead space. Anaesthesia 2007;62:575-580.

39. Austin PD, Hand KS, Elia M. Systematic review and meta-analysis of the risk of microbial contamination of parenteral doses prepared under aseptic techniques in clinical and pharmaceutical environments: an update. J Hosp Infect 2015;91:306-318.

40. Jelacic S, Bowdle A, Nair BG, Kusulos D, Bower L, Togashi K. A system for anesthesia drug administration using barcode technology: the Codonics Safe Label System and Smart Anesthesia Manager. Anesth Analg 2015;121:410-421.

41. Haas RE, Beitz E, Reed A, et al. No bacterial growth found in spiked intravenous fluids over an 8-hour period. Am J Infect Control 2017;45:448-450.

42. Siegel JD, Rhinehart E, Jackson M, Chiarello L, Committee HCICPA. 2007 Guideline for isolation precautions: preventing transmission of infectious agents in health care settings. Am J Infect Control 2007;35:S65-S164.

43. Safe injection practices to prevent transmission to patients. Centers for Disease Control and Prevention website. www.cdc.gov/injectionsaf ety/ip07_standardprecaution.html. Published 2011. Accessed October 24, 2018.

44. Dolan SA, Felizardo G, Barnes S, et al. APIC position paper: safe injection, infusion, and medication vial practices in health care. Am J Infect Control 2010;38:167-172.

45. Commission J. Preventing infection from the misuse of vials. Sentinel Event Alert 2014:1-6.

46. AANA. Safe Injection Guidelines for Needle and Syringe Use. 2014.

47. Stackhouse R, Beers R, Brown D, et al. Recommendations for Infection Control for the Practice of Anesthesiology, 3rd ed. www.asahq.org/ standards-and-guidelines/resources-from-asa-committees\#ic

48. Association of Anaesthetists of Great Britain and Ireland (AAGBI). Infection Control in Anaesthesia. Anaesthesia 2008;63:1027-1036.

49. Greeley RD, Semple S, Thompson ND, et al. Hepatitis B outbreak associated with a hematology-oncology office practice in New Jersey, 2009. Am J Infect Control 2011;39:663-670.

50. CDC. Acute hepatitis $C$ virus infections attributed to unsafe injection practices at an endoscopy clinic-Nevada, 2007. MMWR Morb Mortal Wkly Rep 2008;57:513-517.

51. Wong MR, Del Rosso P, Heine L, et al. An outbreak of Klebsiella pneumoniae and Enterobacter aerogenes bacteremia after interventional pain management procedures, New York City, 2008. Reg Anesth Pain Med 2010;35:496-499.

52. Pan A, Dolcetti L, Barosi C, et al. An outbreak of Serratia marcescens bloodstream infections associated with misuse of drug vials in a surgical ward. Infect Control Hosp Epidemiol 2006;27:79-82.

53. Gutelius B, Perz JF, Parker MM, Hallack R, Stricof R, Clement EJ, et al. Multiple clusters of hepatitis virus infections associated with anesthesia for outpatient endoscopy procedures. Gastroenterology 2010;139:163-170.

54. Branch-Elliman W, Robillard E, McCarthy G, Gupta K. Direct feedback with the ATP luminometer as a process improvement tool for terminal cleaning of patient rooms. Am J Infect Control 2014;42:195-197.

55. Germain JM, Carbonne A, Thiers V, et al. Patient-to-patient transmission of hepatitis $\mathrm{C}$ virus through the use of multidose vials during general anesthesia. Infect Control Hosp Epidemiol 2005;26:789-792.

56. Katzenstein TL, Jørgensen LB, Permin H, et al. Nosocomial HIVtransmission in an outpatient clinic detected by epidemiological and phylogenetic analyses. AIDS 1999;13:1737-1744.

57. Samandari T, Malakmadze N, Balter S, et al. A large outbreak of hepatitis B virus infections associated with frequent injections at a physician's office. Infect Control Hosp Epidemiol 2005;26:745-750.

58. Lagging LM, Aneman C, Nenonen N, et al. Nosocomial transmission of HCV in a cardiology ward during the window phase of infection: an epidemiological and molecular investigation. Scand J Infect Dis 2002;34:580-582.

59. Moore ZS, Schaefer MK, Hoffmann KK, et al. Transmission of hepatitis $\mathrm{C}$ virus during myocardial perfusion imaging in an outpatient clinic. Am J Cardiol 2011;108:126-132.

60. Krause G, Trepka MJ, Whisenhunt RS, Katz D, Nainan O, Wiersma ST, et al. Nosocomial transmission of hepatitis $\mathrm{C}$ virus associated with the use of multidose saline vials. Infect Control Hosp Epidemiol 2003;24:122-127.

61. Hodgson ES, Ruis-Frutos C. A case report of contaminated operating theatre multipurpose equipment: a potential hazard for health care workers. Ann Occup Hyg 1991;35:341-346.

62. Rowlands J, Yeager MP, Beach M, Patel HM, Huysman BC, Loftus RW. Video observation to map hand contact and bacterial transmission in operating rooms. Am J Infect Control 2014;42:698-701.

63. Birnbach DJ, Rosen LF, Fitzpatrick M, Carling P, Munoz-Price LS. The use of a novel technology to study dynamics of pathogen transmission in the operating room. Anesth Analg 2015;120:844-847.

64. Borer A, Gilad J, Meydan N, et al. Impact of active monitoring of infection control practices on deep sternal infection after open-heart surgery. Ann Thorac Surg 2001;72:515-520.

65. Chen LF, Vander Weg MW, Hofmann DA, Reisinger HS. The Hawthorne effect in infection prevention and epidemiology. Infect Control Hosp Epidemiol 2015;36:1444-1450.

66. Srigley JA, Furness CD, Baker GR, Gardam M. Quantification of the Hawthorne effect in hand hygiene compliance monitoring using an electronic monitoring system: a retrospective cohort study. BMJ Qual Saf 2014;23:974-980.

67. Rampersad SE, Martin LD, Geiduschek JM, Weiss GK, Bates SW. Video observation of anesthesia practice: a useful and reliable tool for quality improvement initiatives. Paediatr Anaesth 2013;23:627-633.

68. Martin LD, Rampersad SE, Geiduschek JM, Zerr DM, Weiss GK. Modification of anesthesia practice reduces catheter-associated bloodstream infections: a quality improvement initiative. Paediatr Anaesth 2013;23:588-596.

69. Friedman Z, Katznelson R, Devito I, Siddiqui M, Chan V. Objective assessment of manual skills and proficiency in performing epidural anesthesia-video-assisted validation. Reg Anesth Pain Med 2006;31:304-310.

70. Linam WM, Margolis PA, Atherton H, Connelly BL. Qualityimprovement initiative sustains improvement in pediatric health care worker hand hygiene. Pediatrics 2011;128:e689-e698.

71. Weinger MB, Englund CE. Ergonomic and human factors affecting anesthetic vigilance and monitoring performance in the operating room environment. Anesthesiology 1990;73:995-1021.

72. Cabana MD, Rand CS, Powe NR, et al. Why don't physicians follow clinical practice guidelines? A framework for improvement. JAMA 1999;282:1458-1465.

73. Beatty PC, Beatty SF. Anaesthetists' intentions to violate safety guidelines. Anaesthesia 2004;59:528-540.

74. Pennathur PR, Thompson D, Abernathy JH, et al. Technologies in the wild (TiW): human factors implications for patient safety in the cardiovascular operating room. Ergonomics 2013;56:205-219.

75. Carthey J, Walker S, Deelchand V, Vincent C, Griffiths WH. Breaking the rules: understanding non-compliance with policies and guidelines. BMJ 2011;343:d5283.

76. Hysong SJ, Kell HJ, Petersen LA, Campbell BA, Trautner BW. Theorybased and evidence-based design of audit and feedback programmes: examples from two clinical intervention studies. BMJ Qual Saf 2017;26:323-334.

77. Dolan SA, Heath J, Potter-Bynoe G, Stackhouse RA. Infection prevention in anesthesia practice: a tool to assess risk and compliance. Am J Infect Control 2013;41:1077-1082.

78. Derickson R, Fishman J, Osatuke K, Teclaw R, Ramsel D. Psychological safety and error reporting within Veterans Health Administration hospitals. J Patient Saf 2015;11:60-66.

79. Gurses AP, Seidl KL, Vaidya V, et al. Systems ambiguity and guideline compliance: a qualitative study of how intensive care units follow 
evidence-based guidelines to reduce healthcare-associated infections. Qual Saf Health Care 2008;17:351-359.

80. Russell CD, Young I, Leung V, Morris K. Healthcare workers' decisionmaking about transmission-based infection control precautions is improved by a guidance summary card. J Hosp Infect 2015;90:235-239.

81. Denton A, Topping A, Humphreys P. Evolution of an audit and monitoring tool into an infection prevention and control process. J Hosp Infect 2016;94:32-40.

82. Lim G, Krohner RG, Metro DG, Rosario BL, Jeong JH, Sakai T. Lowfidelity haptic simulation versus mental imagery training for epidural anesthesia technical achievement in novice anesthesiology residents: a randomized comparative study. Anesth Analg 2016;122:1516-1523.

83. Forrest FC, Taylor MA, Postlethwaite K, Aspinall R. Use of a highfidelity simulator to develop testing of the technical performance of novice anaesthetists. Br J Anaesth 2002;88:338-344.

84. Burtscher MJ, Manser T, Kolbe M, et al. Adaptation in anaesthesia team coordination in response to a simulated critical event and its relationship to clinical performance. Br J Anaesth 2011;106:801-806.

85. Edwards VR. Preventing and managing healthcare-associated infections: linking collective leadership, good management, good data, expertise, and culture change. J Hosp Infect 2016;94:30-31.

86. Cunningham D, Brilli RJ, McClead RE, Davis JT. the safety stand-down: a technique for improving and sustaining hand hygiene compliance among health care personnel. J Patient Saf $J$ Patient Saf 2018;14:107-111.

87. Brewster L, Tarrant C, Dixon-Woods M. Qualitative study of views and experiences of performance management for healthcare-associated infections. J Hosp Infect 2016;94:41-47.

88. Armellino D, Hussain E, Schilling ME, et al. Using high-technology to enforce low-technology safety measures: the use of third-party remote video auditing and real-time feedback in healthcare. Clin Infect Dis 2012;54:1-7.

89. Ford S, Birmingham E, King A, Lim J, Ansermino JM. At-a-glance monitoring: covert observations of anesthesiologists in the operating room. Anesth Analg 2010;111:653-658.

90. Srigley JA, Gardam M, Fernie G, Lightfoot D, Lebovic G, Muller MP. Hand hygiene monitoring technology: a systematic review of efficacy. J Hosp Infect 2015;89:51-60.

91. Rodriguez-Aldrete D, Sivanesan E, Banks S, et al. Recurrent visual electronic hand hygiene reminders in the anesthesia work area. Infect Control Hosp Epidemiol 2016;37:872-874.

92. Eckstein BC, Adams DA, Eckstein EC, et al. Reduction of Clostridium difficile and vancomycin-resistant Enterococcus contamination of environmental surfaces after an intervention to improve cleaning methods. BMC Infect Dis 2007;7:61.

93. Goodman ER, Platt R, Bass R, Onderdonk AB, Yokoe DS, Huang SS. Impact of an environmental cleaning intervention on the presence of methicillin-resistant Staphylococcus aureus and vancomycin-resistant enterococci on surfaces in intensive care unit rooms. Infect Control Hosp Epidemiol 2008;29:593-599.

94. Carling PC, Parry MM, Rupp ME, et al. Improving cleaning of the environment surrounding patients in 36 acute care hospitals. Infect Control Hosp Epidemiol 2008;29:1035-1041.

95. Carling PC, Parry MF, Bruno-Murtha LA, Dick B. Improving environmental hygiene in 27 intensive care units to decrease multidrug-resistant bacterial transmission. Crit Care Med 2010;38:1054-1059.

96. Munoz-Price LS, Birnbach DJ, Lubarsky DA, et al. Decreasing operating room environmental pathogen contamination through improved cleaning practice. Infect Control Hosp Epidemiol 2012;33:897-904.

97. Sitzlar B, Deshpande A, Fertelli D, Kundrapu S, Sethi AK, Donskey CJ. An environmental disinfection odyssey: evaluation of sequential interventions to improve disinfection of Clostridium difficile isolation rooms. Infect Control Hosp Epidemiol 2013;34:459-465.

98. Guerrero DM, Carling PC, Jury LA, Ponnada S, Nerandzic MM, Donskey CJ. Beyond the Hawthorne effect: reduction of Clostridium difficile environmental contamination through active intervention to improve cleaning practices. Infect Control Hosp Epidemiol 2013;34:524-526.

99. Trajtman AN, Manickam K, Macrae M, Bruning NS, Alfa MJ. Continuing performance feedback and use of the ultraviolet visible marker to assess cleaning compliance in the healthcare environment. $J$ Hosp Infect 2013;84:166-172.

100. Kundrapu S, Sunkesula V, Sitzlar BM, Fertelli D, Deshpande A, Donskey CJ. More cleaning, less screening: evaluation of the time required for monitoring versus performing environmental cleaning. Infect Control Hosp Epidemiol 2014;35:202-204.

101. Carling PC, Huang SS. Improving healthcare environmental cleaning and disinfection: current and evolving issues. Infect Control Hosp Epidemiol 2013;34:507-513.

102. Matlow AG, Wray R, Richardson SE. Attitudes and beliefs, not just knowledge, influence the effectiveness of environmental cleaning by environmental service workers. Am J Infect Control 2012;40:260-262.

103. Miller DM, Youkhana I, Karunaratne WU, Pearce A. Presence of protein deposits on 'cleaned' re-usable anaesthetic equipment. Anaesthesia 2001;56:1069-1072.

104. Biddle C, Robinson K, Pike B, Kammerman M, Gay B, Verhulst B. Quantifying the rambunctious journey of the anesthesia provider's hands during simulated, routine care. Am J Infect Control 2016;44:873-878.

105. Loftus RW, Patel HM, Huysman BC, et al. Prevention of intravenous bacterial injection from health care provider hands: the importance of catheter design and handling. Anesth Analg 2012;115:1109-1119.

106. Cole DC, Baslanti TO, Gravenstein NL, Gravenstein N. Leaving more than your fingerprint on the intravenous line: a prospective study on propofol anesthesia and implications of stopcock contamination. Anesth Analg 2015;120:861-867.

107. Mahida N, Levi K, Kearns A, Snape S, Moppett I. Investigating the impact of clinical anaesthetic practice on bacterial contamination of intravenous fluids and drugs. J Hosp Infect 2015;90:70-74.

108. Henry B, Plante-Jenkins C, Ostrowska K. An outbreak of Serratia marcescens associated with the anesthetic agent propofol. Am J Infect Control 2001;29:312-315.

109. Hilliard JG, Cambronne ED, Kirsch JR, Aziz MF. Barrier protection capacity of flip-top pharmaceutical vials. J Clin Anesth 2013;25:177-180.

110. Ryan AJ, Webster CS, Merry AF, Grieve DJ. A national survey of infection control practice by New Zealand anaesthetists. Anaesth Intensive Care 2006;34:68-74.

111. Munoz-Price LS, Birnbach DJ. Hand hygiene and anesthesiology. Int Anesthesiol Clin 2013;51:79-92.

112. WHO. World Health Organization Guidelines on Hand Hygiene in Healthcare. Geneva, Switzerland: WHO Press; 2009.

113. Scheithauer S, Rosarius A, Rex S, et al. Improving hand hygiene compliance in the anesthesia working room work area: more than just more hand rubs. Am J Infect Control 2013;41:1001-1006.

114. Sahni N, Biswal M, Gandhi K, Yaddanapudi S. Quantification of hand hygiene compliance in anesthesia providers at a tertiary care center in northern India. Am J Infect Control 2015;43:1134-1136.

115. Paulson DS, Fendler EJ, Dolan MJ, Williams RA. A close look at alcohol gel as an antimicrobial sanitizing agent. Am J Infect Control 1999;27:332-338.

116. Koff MD, Corwin HL, Beach ML, Surgenor SD, Loftus RW. Reduction in ventilator associated pneumonia in a mixed intensive care unit after initiation of a novel hand hygiene program. J Crit Care 2011;26:489-495.

117. Munoz-Price LS, Lubarsky DA, Arheart KL, et al. Interactions between anesthesiologists and the environment while providing anesthesia care in the operating room. Am J Infect Control 2013;41:922-924.

118. Reynolds H, Dulhunty J, Tower M, Taraporewalla K, Rickard C. A snapshot of guideline compliance reveals room for improvement: a survey of peripheral arterial catheter practices in Australian operating theatres. J Adv Nurs 2013;69:1584-1594.

119. Loftus RW, Brindeiro BS, Kispert DP, et al. Reduction in intraoperative bacterial contamination of peripheral intravenous tubing through the use of a passive catheter care system. Anesth Analg 2012;115: $1315-1323$. 
120. Association of periOperative Registered Nurses. Guideline for Environmental Cleaning. AORN Guidelines for Perioperative Practice. Denver: AORN; 2018. Pp. 7-28.

121. Clark C, Taenzer A, Charette K, Whitty M. Decreasing contamination of the anesthesia environment. Am J Infect Control 2014;42:1223-1225.

122. Gonzalez EA, Nandy P, Lucas AD, Hitchins VM. Ability of cleaningdisinfecting wipes to remove bacteria from medical device surfaces. Am J Infect Control 2015;43:1331-1335.

123. Rutala WA, Weber DJ. Disinfectants used for environmental disinfection and new room decontamination technology. Am J Infect Control 2013;41:S36-S41.

124. Jones BL, Gorman LJ, Simpson J, et al. An outbreak of Serratia marcescens in two neonatal intensive care units. J Hosp Infect 2000;46:314-319.

125. Cullen MM, Trail A, Robinson M, Keaney M, Chadwick PR. Serratia marcescens outbreak in a neonatal intensive care unit prompting review of decontamination of laryngoscopes. J Hosp Infect 2005;59:68-70.

126. Phillips RA, Monaghan WP. Incidence of visible and occult blood on laryngoscope blades and handles. AANA J. 1997;65241-35246.
127. Negri de Sousa AC, Vilas Boas VA, Levy CE, Pedreira de Freitas MI. Laryngoscopes: evaluation of microbial load of blades. Am J Infect Control 2016;44:294-298.

128. Call TR, Auerbach FJ, Riddell SW, et al. Nosocomial contamination of laryngoscope handles: challenging current guidelines. Anesth Analg 2009;109:479-483.

129. Williams D, Dingley J, Jones C, Berry N. Contamination of laryngoscope handles. J Hosp Infect 2010;74:123-128.

130. Bhatt JM, Peterson EM, Verma SP. Microbiological sampling of the forgotten components of a flexible fiberoptic laryngoscope: what lessons can we learn? Otolaryngol Head Neck Surg 2014;150:235-236.

131. Hill AF, Butterworth RJ, Joiner S, et al. Investigation of variant Creutzfeldt-Jakob disease and other human prion diseases with tonsil biopsy samples. Lancet 1999;353:183-189.

132. Hirsch N, Beckett A, Collinge J, Scaravilli F, Tabrizi S, Berry S. Lymphocyte contamination of laryngoscope blades-a possible vector for transmission of variant Creutzfeldt-Jakob disease. Anaesthesia 2005;60:664-667. 